\title{
PERFORMANCE-BASED ANALYSIS OF EARTH DAMS: PROCEDURES AND APPLICATION TO A SAMPLE CASE
}

\author{
Stefania Sica ${ }^{\text {i) }}$ and Luca Pagano ${ }^{\text {ii) }}$
}

\begin{abstract}
The paper illustrates theoretical and experimental procedures adopted to characterize the seismic response of earth dams by performance-based criteria. The study refers to a real case, the Camastra Dam, a zoned earth dam with vertical clay core, placed in a highly seismic zone of Southern Italy. At first, the analysis objectives have been identified along with the physical quantities needed to achieve them for characterizing dam seismic performance. A theoretical approach, consistent with the identified analysis objectives, has been later selected. The adopted approach is based on continuum mechanics and accounts for coupling between soil skeleton and pore water phase. It is also able to describe the main features of soil response under cyclic loading conditions since it implements an advanced constitutive law for the soil skeleton. Big effort has been paid to the mechanical characterization of the dam materials. In addition to data coming from the interpretation of the laboratory tests performed at the time of dam construction, in situ tests (SASW, Down Hole, DMT) have been recently carried out on the embankment and foundation soils and interpreted consistently with the requirements of the selected theoretical model. Preliminarily, the static stages of the dam lifetime have been numerically simulated to reproduce the behaviour observed in terms of cross-arm settlements and pore water pressures, in order to obtain or verify some soil parameters and initialize the state variables for the simulation of the seismic stages. A seismological study of the dam site provided the expected seismic scenarios in terms of time histories of acceleration, needed as input for the dynamic analyses. The seismic response of the Camastra Dam was finally investigated and discussed in the light of performance-based criteria.
\end{abstract}

Key words: earth dam, earthquake, seismic performance (IGC: D7/E2/E8/H4)

\section{INTRODUCTION}

The procedures for analysing the seismic response of a structure should be consistent with the objectives the prediction is aimed at and with the structure importance. In the case of earth dams, analysis objectives are essentially aimed at verifying to what extent seismic actions could affect the main task of these structures, that is, ensuring water tightness. Earthquakes may induce negligible effects or decrease water tightness, from limiting dam efficiency up to disaster. The amount of such effects is mainly linked to earthquake characteristics and dam vulnerability.

The suitable theoretical approaches should predict the damage typologies (and related physical quantities) that may affect dam water tightness. Damage typologies affecting water tightness may be derived from past experience, collecting the effects induced by strong earthquakes to earth dams, or may be argued recalling some typical mechanisms related to the operational stages.

Global sliding mechanisms, freeboard loss due to permanent settlements (e.g., Resendiz et al., 1982; Ozkan,
1998; Fujii et al., 2000; Paoliani, 2001; Singh et al., 2005), fractures of the watertightness elements (e.g., Paoliani, 2001) followed by erosion phenomena, and liquefaction ${ }^{1}$ of the embankment (e.g., Seed, 1979; Fujii et al., 2000; Singh et al., 2005) or foundation soils are the most feared seismic-induced phenomena which may significantly affect dam water tightness.

All the above phenomena require predictions in terms of permanent settlements, stress states and pore water pressures for all seismic scenarios expected at the dam site. The prediction of the permanent settlement at the dam crest, typically carried out in plane strain conditions, may be adopted for checking freeboard loss and also (in its meaning of medium vertical strain) as an effective indicator of the dam performance with respect to other damage mechanisms that are very difficult to simulate

\footnotetext{
${ }^{1}$ Liquefaction of the construction soils have been often observed in old hydraulic fill dams made of loose sands and placed in highly seismic areas (Seed, 1979). Modern earth dams are, in principle, less susceptible to liquefaction since built by controlled compaction techniques and proper grain size distribution of the coarse grained materials constituting the shells and filters.
}

i) Assistant Professor, PhD, Dipartimento di Ingegneria, Università degli Studi del Sannio, Italy (stefsica@unisannio.it).

ii) Assistant Professor, PhD, Dipartimento di Ingegneria Idraulica, Geotecnica ed Ambientale, Università degli Studi di Napoli "Federico II", Italy.

The manuscript for this paper was received for review on January 11, 2008; approved on September 29, 2009.

Written discussions on this paper should be submitted before July 1, 2010 to the Japanese Geotechnical Society, 4-38-2, Sengoku, Bunkyo-ku, Tokyo 112-0011, Japan. Upon request the closing date may be extended one month. 
(e.g., vertical fractures of the embankment due to differential settlements among different cross-sections, fractures at the contact between the embankment and structural elements). The permanent settlement of the dam crest is also a suitable indicator of dam performance to characterize dam's mechanical response under different seismic scenarios.

The outlined seismic-induced phenomena may be verified one by one through different simplified procedures. For instance, the pseudo-static (Terzaghi, 1950; Ambraseys, 1960; Seed and Martin, 1966) or pseudo-dynamic approaches (Newmark, 1965; Makdisi and Seed, 1978; Yegian et al., 1991) may be adopted to verify global sliding phenomena; the pseudo-dynamic approach to estimate seismic-induced settlements; empirical correlations may be used to estimate liquefaction occurrence (Seed and Idriss, 1971; Iwasaki et al., 1982; Youd et al., 2001; Idriss and Boulanger, 2004).

In recent decades the development of more comprehensive constitutive models (Mroz, 1967; Mroz et al., 1981; Prevost, 1978; Prevost, 1985; Aubry et al., 1982; Dafalias and Popov, 1975; Dafalias and Harrmann, 1982; Zienkiewicz and Shiomi, 1984; Pastor et al., 1990), describing important features observed at the soil element level (such as non linearity, non reversibility, stress-path dependency, hysteresis, susceptibility to cyclic mobility and liquefaction), and the implementation of coupled dynamic formulation in robust numerical algorithms and computer codes, provide more refined tools to investigate simultaneously the different aspects related to the seismic performance of earth dams.

These approaches are suitable to describe dam response under the seismic actions ${ }^{2}$, since they provide at the same time predictions in terms of stresses, plastic strains, pore water pressures, permanent displacements. For a given earthquake all verifications may be, hence, attained by interpreting the results of a unique analysis. In addition, coupling between soil-skeleton and pore water enables one to analyse the effects of possible post-seismic consolidation phenomena.

Such "advanced approaches" require the quantification of several parameters and the initialization of both stresses and state variables. If the simulation of the static stages is carried out by best-fitting the dam's observed behaviour in terms of settlements and pore water pressures (e.g., Pagano et al., 1998; Pagano et al., 2006), the initial stage of the simulation process allows the quantification of some model parameters and the investigation of the dam pre-seismic safety conditions. At the same time, preseismic stresses and state variables are provided.

The paper accounts for the methodology followed by the authors to evaluate the seismic performance of a real case: the Camastra Dam. It is a zoned earth dam with an internal clay core and rockfill shells. The dam was selected by the authors as a sample dam in the multidisciplinary research project VIA (Vulnerability of Infrastructures

\footnotetext{
${ }^{2}$ In such approaches, the seismic actions are usually represented as time-histories of acceleration.
}

and Environment) supported by the National Institute of Geophysics and Volcanology (INGV-GNDT) in Italy.

The structure of the paper covers the following topics. First, the essential features of the Camastra Dam are presented. The theoretical tools selected to predict the seismic behaviour of the sample dam are subsequently described. Details are later provided on the experimental procedures to characterize soil parameters required by the selected model; the definition of the expected seismic scenarios at the dam site is accounted for; the seismic performance of the dam is finally discussed on the basis of the computed results.

\section{THE CAMASTRA DAM}

The Camastra Dam is a zoned earth dam close to the city of Potenza in Southern Italy. It is characterized by a maximum height of about $54 \mathrm{~m}$ and a reservoir capacity of $42 \times 10^{6} \mathrm{~m}^{3}$ (Fig. 1(a)). An internal vertical core made of silty sand and compacted slightly wet of the optimum (average properties are: plasticity index $I_{\mathrm{p}}=17 \%$, liquid limit $w_{1}=37 \%$, permeability coefficient $k \cong 10^{-8} \mathrm{~cm} / \mathrm{s}$, water content at the optimum of Proctor standard $w_{\text {opt }}=$ $16 \%$, water content after compaction $w=18 \%$, friction angle $\phi^{\prime}=30^{\circ}$ ) is supported by sandy gravel shells (friction angle $\phi^{\prime}=40^{\circ}$ ). The dam foundation (Fig. 1(b)) is made of a calcareous-clayey formation (flysch of Corleto Perticara) coming from the left abutment and a complex arenaceous-clay formation (the so-called Serra Palazzo formation) from the right abutment. The two rock formations meet each other below the dam base in a very chaotic way.

During the construction, the dam body was instrumented to monitor internal settlements, pore water pressures and total vertical stresses.

The dam was built in the period July 1963-November 1964 when there was no awareness about the real seismicity of the reservoir site. The national regulation in force at that time did not consider the dam site as a seismic one. It

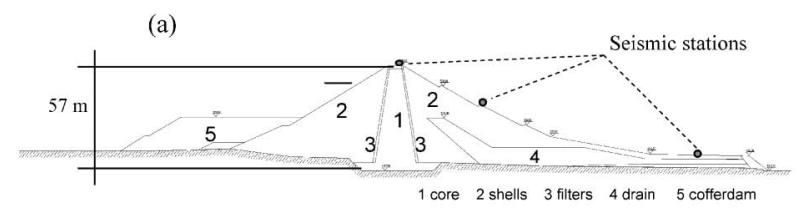

(b)

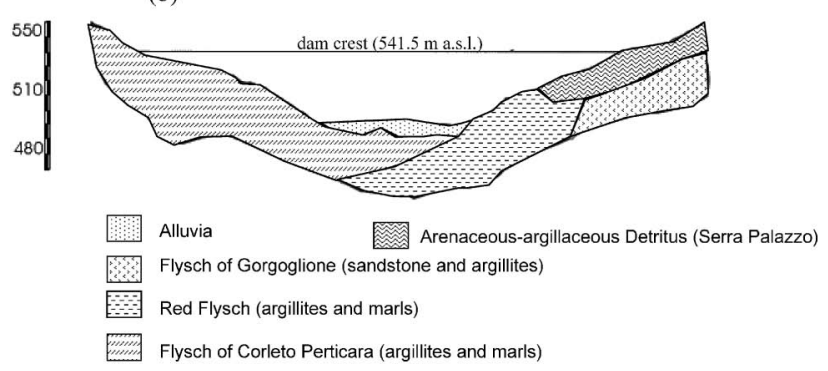

Fig. 1. Camastra Dam: (a) maximum cross section and (b) geological section along the dam longitudinal axis 

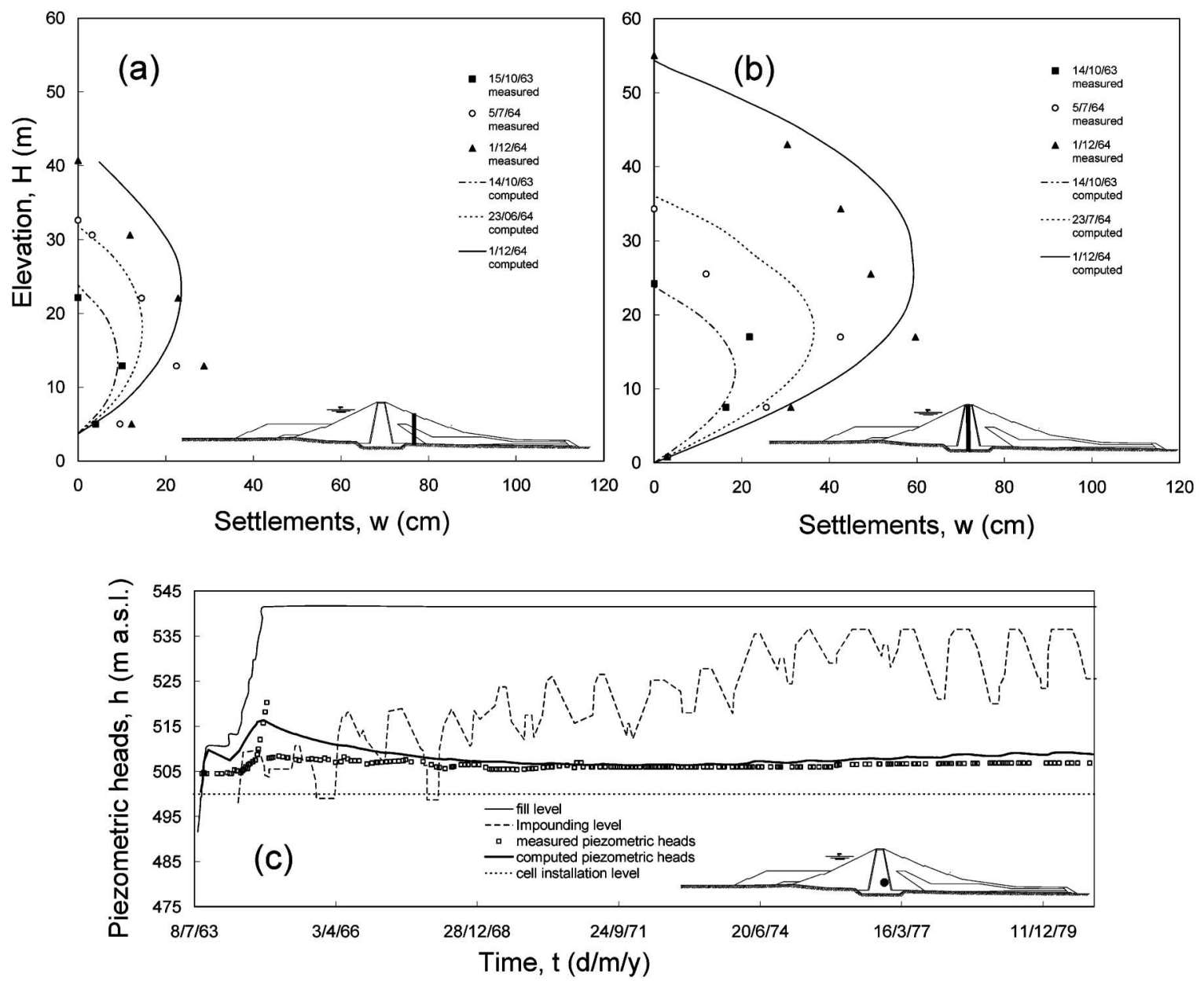

Fig. 2. Static behaviour of the Camastra Dam: (a) settlements measured during the construction at the cross-arm located in the downstream shell, (b) settlements measured during the construction at the cross-arm located in the core and (c) piezometric heads measured in the core during the construction and operational stages

is a typical case in Italy of an existing dam designed without taking seismic loads into account and needing, after almost half a century of operation, to be seismically verified due to a substantial update of the seismic classification of the dam site.

Figure 2 represents the settlements measured during the construction stages at the two cross-arm verticals located in the downstream (Fig. 2(a)) and in the core (Fig. 2(b)). Figure 2(c) plots the piezometric heads measured in one point of the core during the construction and operational stages. In the same figure, fill-height and water table evolutions have been represented.

In July 2002 a seismic monitoring system was installed at the Camastra Dam site. Three accelerometers were placed along the dam's main cross section in correspondence to the downstream base, mid-height bank and crest (Fig. 1(a)) to acquire information on frequency filtering and amplification effects exerted by the dam embankment on the incoming signals. Two accelerometers were installed on the lateral abutments of the dam to detect the seismic response of the basement formations. Figure 3 shows the response spectra (at $5 \%$ of structural damping) of the accelerations recorded at the dam site during the Molise earthquake on October 31, 2002. The signals refer

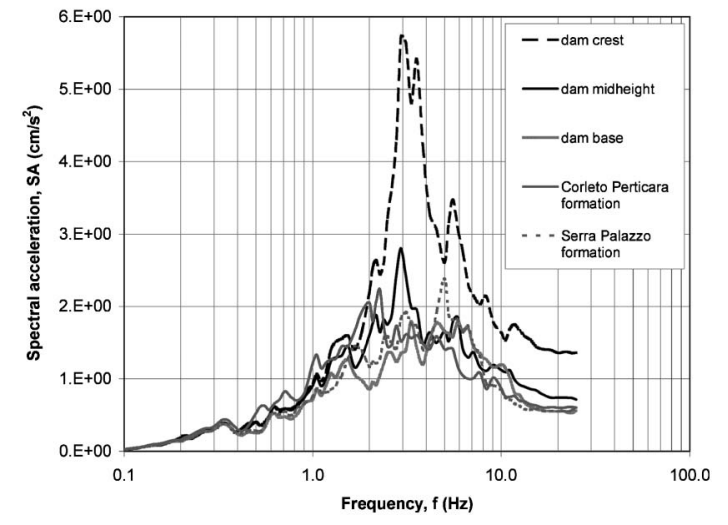

Fig. 3. Response spectra of recorded accelerations at Camastra Dam during the main shock of the Molise earthquake (October 31, 2002)

to the horizontal acceleration recorded in the transversal direction (upstream-downstream) of the dam.

\section{SELECTED MODEL TO INVESTIGATE THE CAMASTRA DAM PERFORMANCE}

The approach adopted to predict the Camastra Dam 
seismic response is based on the u-p version of the Biot generalized consolidation theory, where $\mathbf{u}$ represents the displacement vector of the solid phase and $p$ the pore water pressure. The field equations characterizing the boundary value problem consist of overall dynamic equilibrium, water equilibrium, water continuity, compatibility, constitutive law and generalized Darcy's law. Further details are provided in APPENDIX 1.

The constitutive law adopted to model the soil skeleton behaviour of the construction soils is the so-called Hujeux model (Aubry et al., 1982; Aubry and Modaressi, 1996). The model, developed in the framework of the incremental elastoplasticity, is characterized by both isotropic and kinematic hardening. It enables one to describe the main features of soils under dynamic loads. Details about the model are provided in APPENDIX 2.

The $\mathbf{u}-\mathrm{p}$ formulation of the Biot generalized consolidation theory combined to the Hujeux model as constitutive law, has been solved numerically by the finite element method and implemented in the GEFDYN code (Aubry and Modaressi, 1996). The program has been tested to date by modelling different case-histories among which the Lower San Fernando Dam failure (Aubry et al., 1991), the centrifuge models 1,2 and 7 of the VELACS project (Aubry et al., 1993) and the seismic response of the El Infiernillo Dam (Sica et al., 2008).

The disadvantage of using an advanced constitutive model to describe soil skeleton response is the definition of several soil parameters and the need for a detailed geotechnical characterization of the construction soils. The Hujeux model, for instance, requires the definition of the following parameters (see APPENDIX 2 for their meaning):

1) $K_{\text {ref }}, G_{\text {ref }}, n, p_{\text {ref }}$ to characterize soil stiffness at small strains;

2) $\phi^{\prime}, \beta, p_{\mathrm{co}}, d, b$ to describe soil critical state and plastic response;

3) $\psi, a_{1}, a_{2}, \alpha, c$ to define flow rule and isotropic (volumetric and deviatoric) hardening;

4) $r_{\mathrm{k}}^{\mathrm{el}}, r_{\mathrm{k}}^{\mathrm{hys}}, r_{\mathrm{k}}^{\mathrm{mob}}, r_{4}^{\mathrm{el}}$ representing threshold domains.

The above parameters have been often grouped
(Hicher and Michali, 1996; Lopez-Caballero and Modaressi, 2008) in two categories. A first category includes the parameters $K_{\mathrm{ref}}, G_{\mathrm{ref}}, \mathrm{v}, p_{\mathrm{ref}}, \phi^{\prime}, \beta, p_{\mathrm{co}}, d, \psi, r_{\mathrm{k}}^{\mathrm{el}}$, $r_{\mathrm{k}}^{\mathrm{hys}}, r_{\mathrm{k}}^{\mathrm{mob}}, r_{4}^{\mathrm{el}}$ which may be straightforwardly obtained by interpreting the experimental stress-strain curves. A second category includes those parameters $\left(b, a_{1}, a_{2}, \alpha, c\right)$ describing the evolution of the hardening variables for which more complex interpretative procedures are required, involving iterative matching of numerical predictions to experimental curves.

Detailed explanation on the criteria and procedures adopted to determine the model parameters for the Camastra Dam soils will be provided in the following section.

\section{EXPERIMENTAL CHARACTERIZATION OF THE DAM SOILS}

Most of the laboratory tests carried out at the time of dam construction on rockfill and core materials are triaxial tests. A large triaxial apparatus developed at that time by the Department of Geotechnical Engineering of the University of Naples was adopted for testing the rockfill soils of the shells. In Fig. 4 the results obtained from such tests have been interpreted in terms of secant Young modulus versus the axial strain.

In the performed research activity big effort was devot-

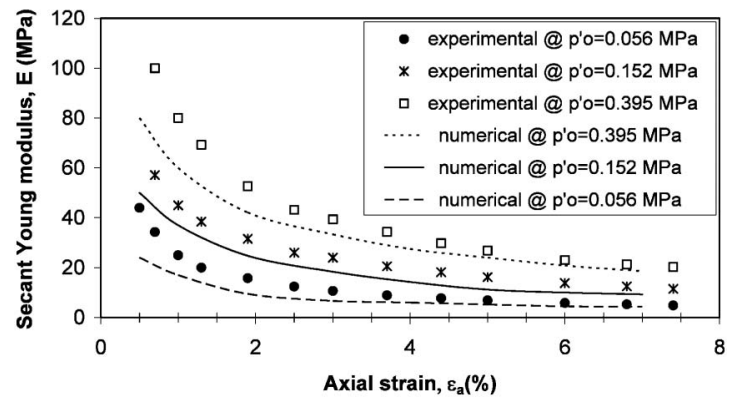

Fig. 4. Experimentally and numerically computed axial stiffness for the shell materials

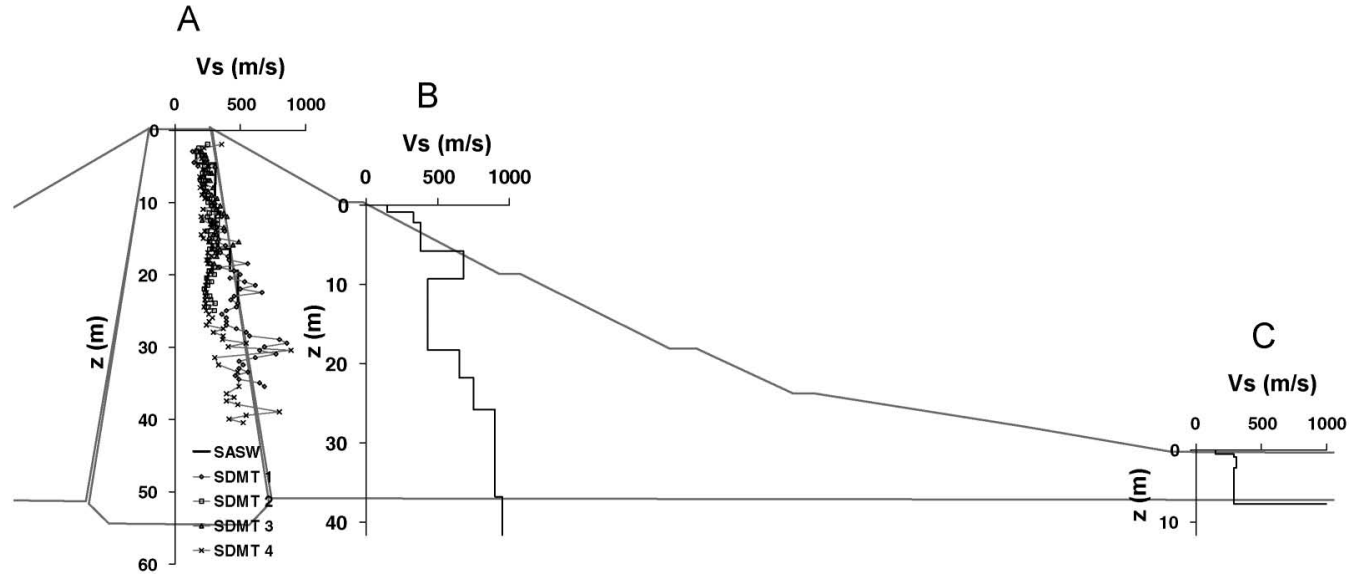

Fig. 5. Shear wave velocities measured at the Camastra Dam by SASW and DH tests 
ed to the proper estimation of soil stiffness at small strains because this parameter may strongly affect frequency and amplitude changes that a seismic signal (weak or strong) experiences during its propagation from the base to the top of the dam. As regards the core soils, SASW tests (Fig. 5) were performed at the dam crest along the longitudinal axis of the core to investigate the changes of core stiffness with depth (different alignments set up with 2 receivers and 2 vibration sources). Investigation was deepened down to $25 \mathrm{~m}$ below the dam crest.

Down-hole tests were carried out by adopting the seismic dilatometer (SDMT) (Mayne et al., 1999). Four verticals of the core were investigated by the SDMT test carried out from the crest down to $40 \mathrm{~m}$. From Fig. 5 the satisfying correspondence between the shear wave values $V_{\mathrm{s}}$ measured in the core by the SASW and SDMT technique could be observed.

The profile of $V_{\mathrm{s}}$ along the core axis shows that the shear wave velocity $V_{\mathrm{s}}$ is almost constant in the first $27 \mathrm{~m}$ below the dam crest, assuming an average value of 250 $\mathrm{m} / \mathrm{s}$; between the depth of 27 and $40 \mathrm{~m}, V_{\mathrm{s}}$ starts to increase reaching $480 \mathrm{~m} / \mathrm{s}$ on average. The particular $V_{\mathrm{s}}$ profile observed along the core axis ( $V_{\mathrm{s}}$ almost constant in the first 20-30 meters from the top and then starts to increase with depth) has been also observed for other zoned earth dams. For example, the Bilancino Dam in Italy (Vinale et al., 1995). This behaviour may be partly attributed to core discharge due to arch effects. These phenomena are often observed in zoned earth dams with core and shells having significantly different stiffness values.

As regards the shells, it was not possible to perform SDMT tests because the grain size prevented the insertion of the dilatometer plate. Only SASW tests were, hence, carried out at two different blankets of the downstream shell (location B and C in Fig. 5). The $V_{\mathrm{s}}$ values (500 up to $1000 \mathrm{~m} / \mathrm{s}$ ) found in the downstream shell at location $\mathrm{B}$ enhance the higher shell stiffness compared to the core one. From the $V_{\mathrm{s}}$ values obtained at the location $\mathrm{C}$, it could be argued that the foundation soil may be regarded as a bedrock from the viewpoint of the seismic wave propagation. The trends of $V_{\mathrm{s}}$ with $p^{\prime}$ have been transformed in relationships between the initial shear stiffness $G_{0}$ and the mean effective stress $p^{\prime}$. To such a scope, the effective stresses have been computed by linear elastic finite element analyses, assigning to the core and shells the elastic parameters measured at small strains.

The determination of the hardening parameters was carried out by estimating first a suitable $G / G_{0}-\gamma$ curve for the soils in hand (Fig. 6) and then by back-analyzing this trend through the Hujeux model.

For the core the $G / G_{0}-\gamma$ relationship was obtained by interpreting two experimental data:

1) the shear modulus at small strains $G_{0}$ obtained from the shear wave velocity measurements of the $\mathrm{DH}$ test and conventionally referred to a value of shear strain $\gamma$ equal to $10^{-5} \%$;

2) the shear modulus at medium strains $G_{\text {med }}$, obtained from the dilatometer modulus provided by the stan-
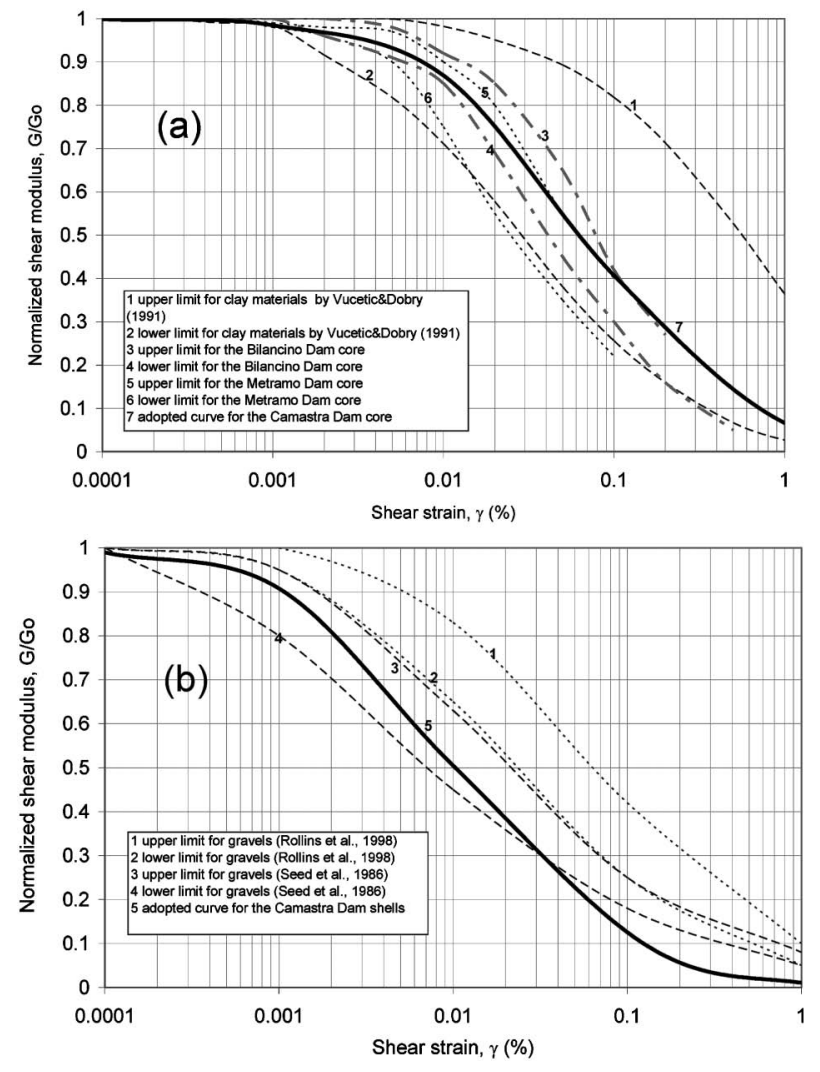

Fig. 6. Normalized shear modulus $G / G_{0}$ of the dam core (a) and shells (b) versus the shear strain $\gamma$

dard DMT test and referred to a value of shear strain $\gamma$ equal to $10^{-1} \%$ (Mayne et al., 1999; Ishihara, 2001).

The $G / G_{0}-\gamma$ curves shown in Fig. 6 were obtained by numerically simulating soil response in 1 cycle undrained (core) and drained (shells) strain-controlled triaxial tests, forcing to fit the two experimental points. The decay law obtained numerically has been compared to typical ranges (Fig. 6) indicated in literature for similar soils (Vucetic and Dobry, 1991).

In the rockfill shells, since no dilatometer test were possible, the $G / G_{0}-\gamma$ curves were completely deduced from literature suggestions (Seed et al., 1986; Rollins et al., 1998). Reference was made to literature also for setting the linear and the volumetric threshold, $\gamma_{1}$ and $\gamma_{\text {vol }}$ respectively, required to compute the Hujeux model parameters $r_{\mathrm{k}}^{\mathrm{el}}$ and $r_{\mathrm{k}}^{\text {hys }}$ (APPENDIX 2).

In conclusion, for the Camastra Dam, the model parameters have been set in the following way:

- $\phi^{\prime}, \beta, p_{\text {co }}, d, \psi$ by interpreting the results of triaxial and oedometric tests, carried out on the core and shell materials during the design and the construction stage;

- $G_{\text {ref }}, K_{\text {ref }}, n$ by interpreting in-situ SASW tests carried out on both core and shell materials, and Down Hole (DH) tests within the core;

- $b$ was set equal to 1 (Cam-Clay yielding surface type) for the core and 0 (Mohr Coulomb yielding surface type) for the shells; 
- $r_{\mathrm{k}}^{\mathrm{el}}, \quad r_{\mathrm{k}}^{\mathrm{hys}}$ were derived from typical literature thresholds of shear strains, (the linear threshold, $\gamma_{1}$, and the volumetric one, $\gamma_{\mathrm{vol}}$ ) based on intrinsic and state variables of the soils; $r_{\mathrm{k}}^{\mathrm{mob}}$ was fixed one-order magnitude greater than $r_{\mathrm{k}}^{\text {hys }}$.

- $a_{1}$ and $a_{2}$ have been set by preliminary defining the decay law of the $G / G_{0}$ ratio with the shear strain $\gamma$ and subsequently modelling it numerically with the Hujeux law.

Dam behaviour observed during the construction and operational stages in terms of settlements and pore water pressures refers to high strain levels. The best-fitting of settlements and pore water pressures shown in Fig. 2 required a further adjustment of some parameters controlling soil non-linear behaviour.

In particular, the stiffness of both shells and core was decreased in order to predict higher displacements in these zones of the dam, consistently with the cross-arm observations during the construction stage. To simultaneously match the higher observed pore water pressures in the core, the stiffness contrast between the core and the shells was also lowered. Such a modification increased the core load (and pore water pressures) by reducing core arching. Pore pressure build-up was, further, increased by enhancing the confinement exerted by the shells on the core, and, consequently, the core mean total stresses. This was obtained by reducing in the shells, the ratio between shear and volumetric stiffness.

The decrease in stiffness of the core was obtained by changing essentially the soil skeleton parameter $\beta$, which regulates the plastic compressibility in the plane $\left(\ln p^{\prime}\right.$, $\left.\varepsilon_{\mathrm{v}}^{\mathrm{p}}\right)$. The decrease in the shell shear stiffness was obtained through changes of the hardening parameters $a_{1}$ and $a_{2}$.

\section{SEISMIC ACTIONS AT THE DAM SITE}

A crucial step in the evaluation of the seismic performance of earth dams is the definition of the input motion. This step involves both seismic hazard and ground response analyses to be performed.

The seismic hazard at the Camastra Dam site was determined by a probabilistic approach (Probabilistic Seismic Hazard Analysis, $\mathrm{PSHA}^{3}$ ) carried out by the seismological team involved in the research project VIA (Calvi, 2004; Convertito and Herrero, 2004). For such a scope, the seimogenetic zones of the Italian seismic zonation ZS4 ${ }^{4}$ (Scandone and Stucchi, 2000; Meletti et al., 2000),

\footnotetext{
3 The PSHA consists in evaluating the annual frequency of exceedance of a physical quantity assumed to be representative of the seismic motion at the bedrock level. Usually, this parameter is assumed to be represented by the maximum acceleration, PGA, on rock. For a specific zone, the annual frequency of exceedance depends on the spatial distribution of the seismogenetic sources and on the seismicity rate. The latter represents the number of earthquakes per year and depends on the area of the seismogenetic source and the magnitude range considered for the zone in hand on the basis of historical data.

4 The seismogenetic zonation ZS4 represented the reference zonation for all seismological studies in Italy up to 2002 and, for this reason, it was adopted even in the research project VIA. Later the ZS4 was replaced by the ZS9 (Meletti and Valensise, 2004). Worth pointing out
}

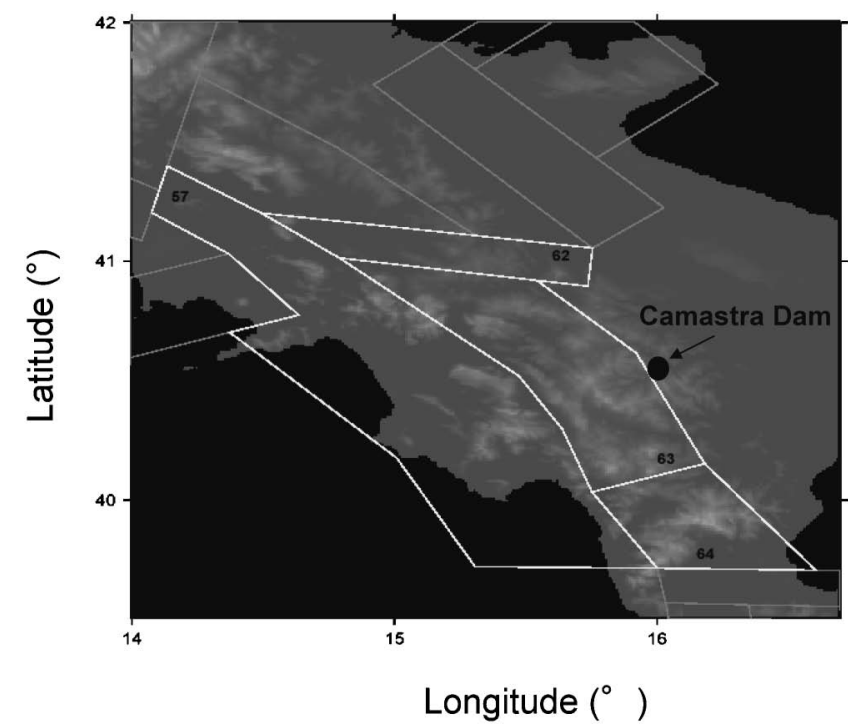

Fig. 7. Seismogenetic zones considered in the probabilistic seismic hazard analysis (PSHA) of the Camastra Dam site. The numbers shown on the map $(57,62,63$ and 64$)$ identify the active zones according to the Italian seismic zonation ZS4

indicated in Fig. 7 with numbers 57, 62, 63 and 64, have been taken into account. By a de-aggregation approach (McGuire, 1995; Convertito and Herrero, 2004) the combination of the parameters characterizing the expected seismic scenarios for fixed return periods, $T_{\mathrm{r}}$, has been defined. These parameters are the magnitude, $M$, the source-to-site distance, $D$, and the peak ground acceleration on rock formation, PGA. From worldwide databases ${ }^{5}$, natural accelerograms with features corresponding to those provided by the de-aggregation study were selected for the zone at hand.

In Fig. 8 the annual frequency of exceedance of the expected events has been represented as a function of the PGA. In Table 1 the values of $M, D$ and PGA of the expected earthquakes are represented for $T_{\mathrm{r}}$ equal to 500 , 1000, 2500 and 5000 years. Seven earthquakes matched the results of the de-aggregation process, among which four occurred in Europe and three in Japan. Details about these earthquakes have been provided in Table 2 . The main parameters (peak ground acceleration PGA, Arias intensity $I_{\mathrm{a}}$, Trifunac duration $t_{\text {strong }}$, response-spectrum $^{6}$ dominant period $T_{\mathrm{p}}$ and frequency $f_{\mathrm{p}}$ ) of these signals are reported in Table 3.

In Figs. 9(a) and (b) the time histories and the Fourier spectra of the input accelerograms have been shown, re-

is that in the zone in hand the two zonations ZS4 and ZS9 provide the same information.

${ }^{5}$ For higher return period ( $>5000$ years) the seismological study provided a seismic event of magnitude $M=6.7$ with a source-site distance lower than $10 \mathrm{Km}$. Since in the Italian ground motion database no record matched the above features, it was necessary to use databases of natural accelerograms recorded in other countries. In particular, reference was made to the European Strong Ground Motion Database and the Kyoshin Network Database.

${ }^{6}$ Response spectra were computed for a structural damping equal to 5 $\%$. 


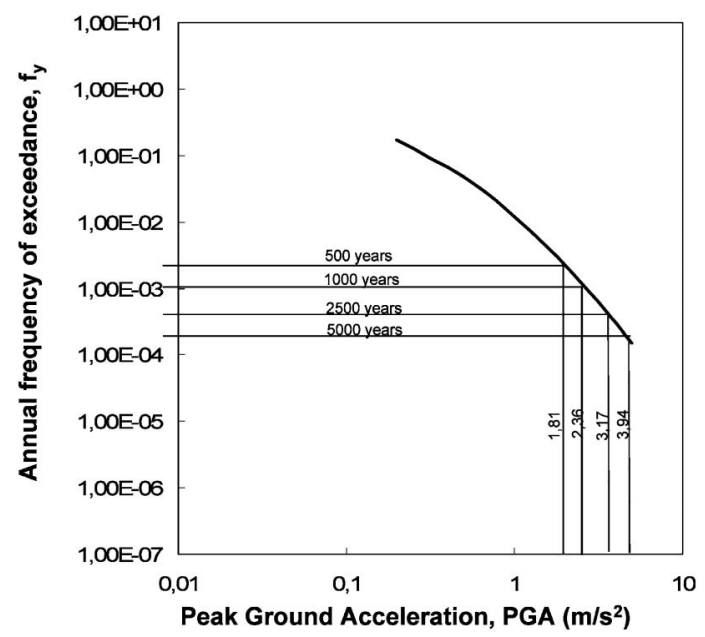

Fig. 8. Annual frequency of exceedance of the expected earthquakes versus the peak ground acceleration, PGA

Table 1. PGA of the expected earthquakes as function of the return period, $T_{\mathrm{r}}$, magnitude, $M$, and source-site distance $D$

\begin{tabular}{c|c|c|c}
\hline$T_{\mathrm{r}}$ (year) & $M$ & $D(\mathrm{Km})$ & $\mathrm{PGA}\left(\mathrm{m} / \mathrm{s}^{2}\right)$ \\
\hline 500 & 5.8 & 8.5 & 1.81 \\
\hline 1000 & 6.1 & 8.5 & 2.36 \\
\hline 2500 & 6.4 & 8.5 & 3.17 \\
\hline 5000 & 6.7 & 8.5 & 3.94 \\
\hline
\end{tabular}

spectively. A very different duration of the strong motion phase (between $3.7 \mathrm{~s}$ and $17.7 \mathrm{~s}$ ) emerges from the time histories of the selected events. The Fourier spectra indicate that most of the signals have a maximum energy content in the range of frequencies from 0.5 to $5 \mathrm{~Hz}$ with the exception of the Montenegro UH accelerogram, that has dominant frequencies between 7 and $20 \mathrm{~Hz}$.

\section{NUMERICAL MODEL AND ANALYSIS STEPS}

The geometry of the main cross section of the Camastra Dam was discretized in 2D with 600 isoparametric 4node elements (Fig. 10). A coupled approach was adopted for the clayey core while the shells were modelled by an uncoupled approach due to their significantly higher permeability.

The construction stage of the dam was simulated by placement of 15 horizontal layers with thickness ranging from 1 to 5 meters. The dead load of each layer was activated following the embankment construction curve.

The water filling was simulated by applying a time dependent hydrostatic distribution of pore water pressure following the height of the reservoir water. On the wet boundary of the core, a normal stress distribution equal to that applied in terms of pore water pressures was also added in order to satisfy the requirement of null effective pressure at the boundary itself. The core base was assumed to be impermeable while the hydraulic condition along the remaining dry boundary of the core was that of a seepage surface (Pagano, 1998). In the upstream shell,

Table 2. Earthquakes provided by the seismological study to characterize the dam site seismicity

\begin{tabular}{l|l|c|c|c|c|l|l}
\hline \multicolumn{1}{c|}{ Earthquake } & Country & $\begin{array}{c}\text { Date } \\
\text { day/month/year }\end{array}$ & $\begin{array}{c}\text { Origin Time } \\
\text { h/min }\end{array}$ & $M_{\mathrm{s}}$ & $\begin{array}{c}\text { Depth } \\
\text { Km }\end{array}$ & Recording station & \multicolumn{1}{c}{$\begin{array}{c}\text { PGA } \\
\text { m/s }\end{array}$ (Channel) } \\
\hline Japan SZO & Japan & $04 / 03 / 1997$ & 12.51 & 5.7 & 6 & Itoh (SZO002) & $1.62(2) / 1.51(1) / 0.82(3)$ \\
\hline Valnerina & Italy & $19 / 09 / 1979$ & 21.35 & 5.8 & 4 & Cascia & $1.51(\mathrm{NS}) / 2.013(\mathrm{WE}) / 1.602(\mathrm{NS})$ \\
\hline Japan MYG & Japan & $26 / 07 / 2003$ & 7.13 & 6.2 & 10 & Ishinomaki (MYG010) & $1.96(2) / 2.50(1) / 2.60(3)$ \\
\hline Friuli Tolmezzo & Italy & $06 / 05 / 1976$ & 20.00 & 6.5 & 6 & Tolmezzo & $3.5(\mathrm{NS}) / 3.1(\mathrm{WE}) / 2.62(\mathrm{UD})$ \\
\hline Montenegro PH & Montenegro & $15 / 04 / 1979$ & 6.19 & 7.0 & 4 & Petrovac-Hotel Oliva & $4.455(\mathrm{NS}) / 3.001(\mathrm{WE}) / 2.086(\mathrm{UD})$ \\
\hline Montenegro UH & Montenegro & $15 / 04 / 1979$ & 6.19 & 7.0 & 4 & Ulcinj-Hotel Olimpic & $2.881(\mathrm{NS}) / 2.362(\mathrm{WE}) / 4.491(\mathrm{UD})$ \\
\hline Japan KGS & Japan & $26 / 03 / 1997$ & 17.31 & 6.3 & 13 & Miyanojoh (KGS005) & $4.93(2) / 4.34(1) / 1.45(3)$ \\
\hline
\end{tabular}

Table 3. Main parameters of the accelerometric signals adopted in the FEM analyses

\begin{tabular}{r|l|c|c|c|c|c|c}
\hline$T_{\mathrm{r}}($ year $)$ & Earthquake & Channel & PGA $\left(\mathrm{m} / \mathrm{s}^{2}\right)$ & $I_{\mathrm{a}}(\mathrm{m} / \mathrm{s})$ & $T_{\mathrm{p}}(\mathrm{s})$ & $f_{\mathrm{p}}(\mathrm{Hz})$ & $t_{\text {strong }}(\mathrm{s})$ \\
\hline 500 & Japan SZO & 2 & 1.62 & 0.27 & 0.30 & 3.33 & 3.71 \\
\hline 800 & Valnerina & WE & 2.01 & 0.20 & 0.20 & 5.00 & 3.96 \\
\hline 1000 & Japan MYG & 1 & 2.50 & 1.00 & 0.14 & 7.14 & 15.46 \\
\hline 2500 & Friuli Tolmezzo & NS & 3.50 & 0.78 & 0.26 & 3.85 & 7.47 \\
\hline$>5000$ & Montenegro PH & NS & 4.45 & 4.40 & 0.44 & 2.27 & 17.77 \\
\hline$>5000$ & Montenegro UH & UD & 4.49 & 2.47 & 0.06 & 16.67 & 15.95 \\
\hline$>5000$ & Japan KGS & 2 & 4.93 & 1.37 & 0.24 & 4.17 & 6.65 \\
\hline
\end{tabular}



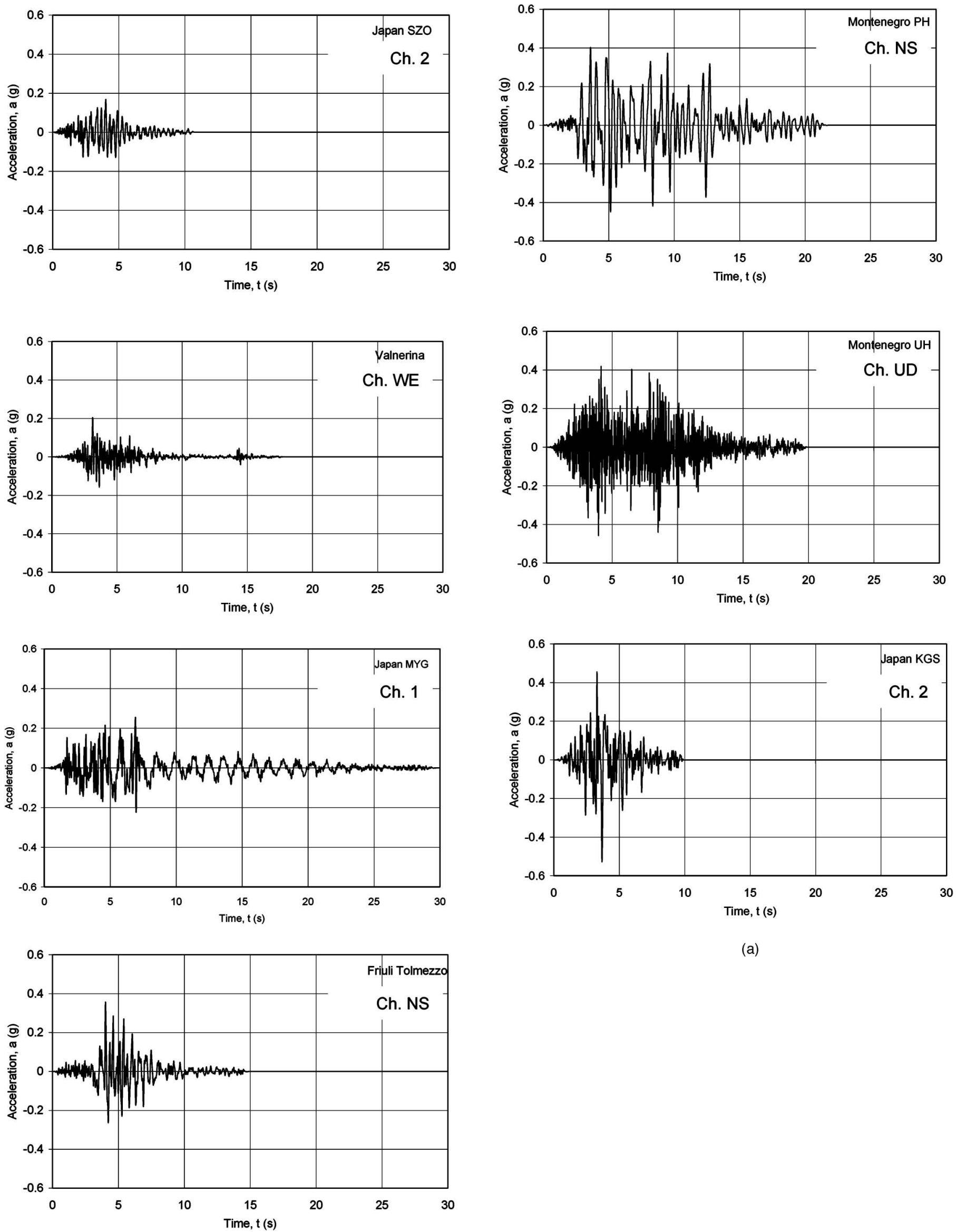

(a)

Fig. 9. Time histories (a) and Fourier amplitude (b) of the reference earthquakes 

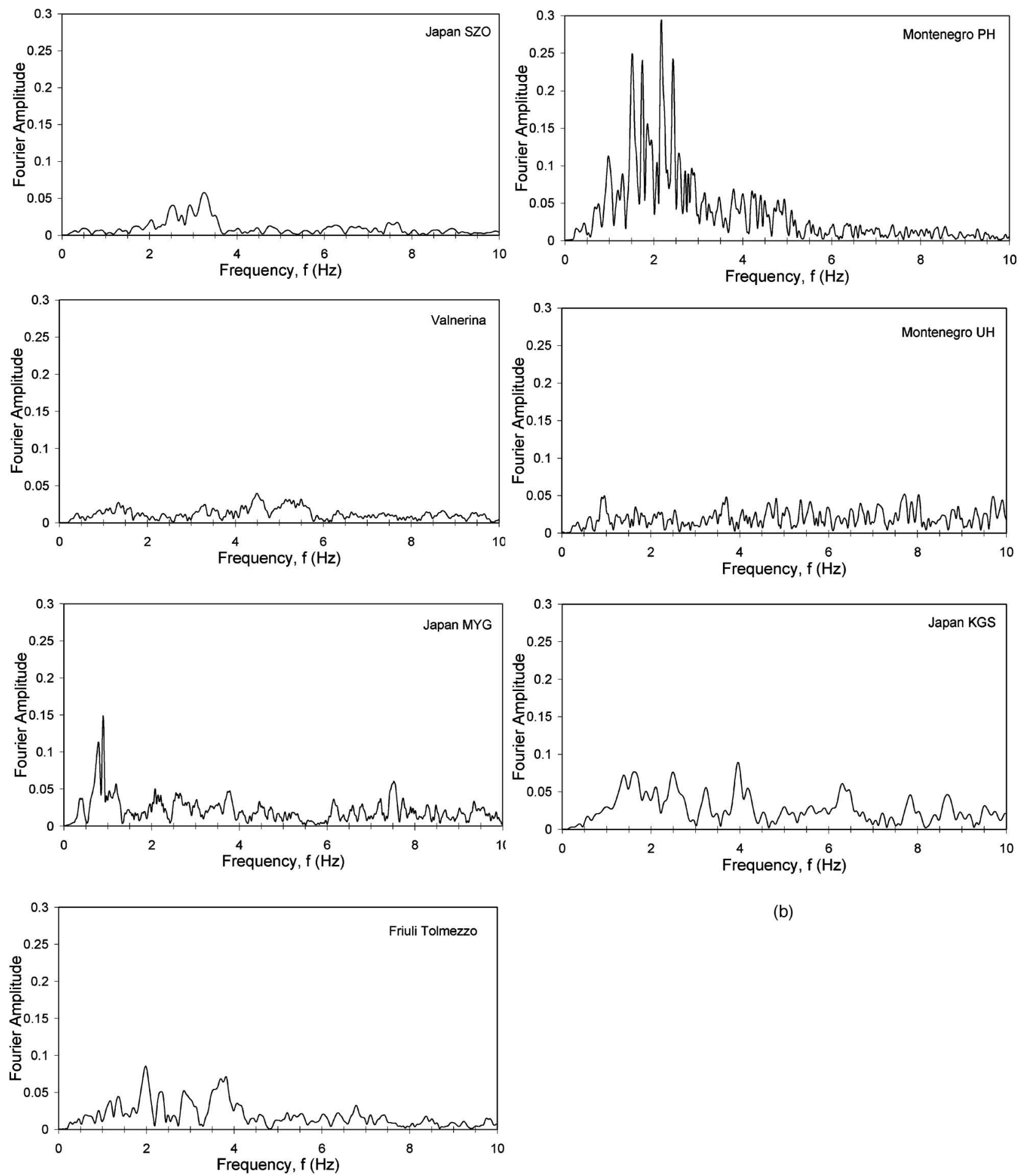

(b)

the action of the water on soil skeleton was simulated by applying buoyant forces in the wet region consistently with the upstream hydrostatic pore water pressure distribution.

During the different stages of the static analysis (construction, first impounding and operation stages) the nodes along the bottom boundary of the FEM model were fixed in both horizontal and vertical direction. During the dynamic stage the same nodes were freed in the horizontal direction in order to activate the absorbing elements. A special version of absorbing elements are implemented in GEFDYN, called paraxial elements (Aubry and Modaressi, 1996). These are linear 2 or 3-node elements developed to simulate the radiation condition at the base of the finite element model by eliminating the elastic waves reflected in the interior of the finite domain by the artificial boundaries of the model. This objective is accomplished by imposing additional actions reproduc- 


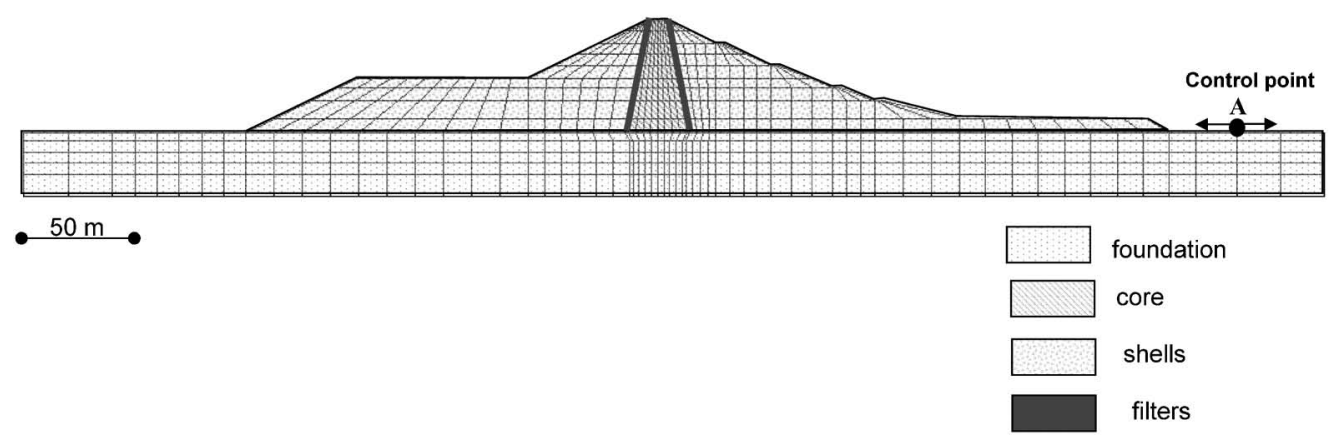

Fig. 10. Finite element mesh of the main cross section of the Camastra Dam

ing the dynamic impedance at the nodes of the model boundary which characterizes the interface between the finite and the infinite domain. The latter is regarded as a 1-phase elastic medium.

Since the high value of the shear wave velocity measured in the foundation soils by the SASW investigation (refer to Vertical $\mathrm{C}$ in Fig. 5) allowed to consider the foundation of the dam as a bedrock, in the dynamic analyses the accelerograms provided by the seismological study have been applied at a control point (point A in Fig. 10) placed on the foundation soil at the elevation of the embankment base. The input signal has been elastically deconvoluted at the bottom of the FEM model and then re-propagated upward.

\section{BACK ANALYSIS OF THE STATIC STAGES}

Interpretation of the traditional laboratory tests (oedometric and undrained triaxial tests on the core soils; drained triaxial tests on the shell materials) and of in situ tests (SASW, DH and DMT tests) allowed a preliminary definition of the required model parameters. Several soil parameters were then updated by a trial-and-error back analysis procedure (e.g., Fig. 2) aimed at fitting time histories and spatial distributions of settlements and piezometric heads, during both construction and operation. Comparisons in terms of settlements, shown in Figs. 2(a) and (b), and in terms of piezometric heads, shown in Fig. 2(c), evidence that the numerical model is able to reproduce satisfactorily the observed static behaviour of the dam.

\section{SEISMIC PERFORMANCE}

In Fig. 11 the time histories of the horizontal acceleration computed in three nodes of the core axis for the Montenegro PH event have been compared. As expected, the signal amplifies when it propagates from the base to the top of the dam embankment. The amplification is very abrupt in the upper five meters, reaching the high value of $1.6 \mathrm{~g}$ at the dam crest. In order to compare the acceleration distributions induced in the embankment by all the signals, Fig. 12 shows the maximum downstream and upstream accelerations predicted for each accelerogram along the core axis. With the exception of the Mon-

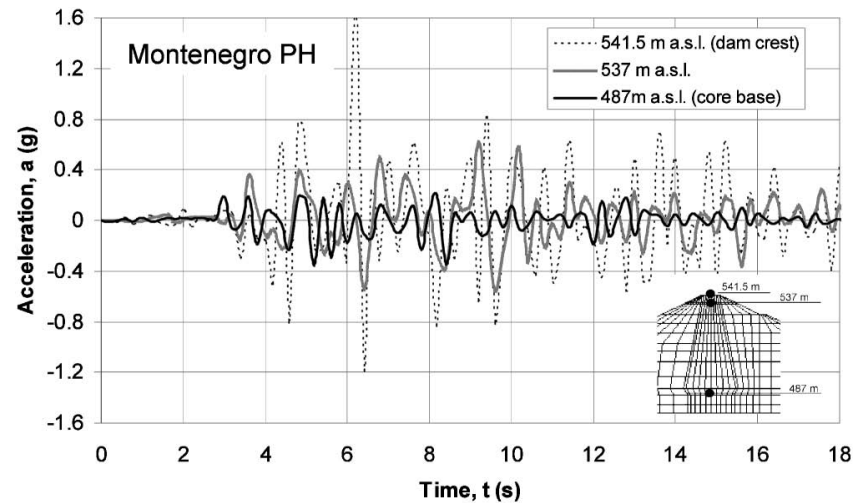

Fig. 11. Acceleration time histories predicted at three points of the core axis for the Montenegro $\mathbf{P H}$ accelerogram

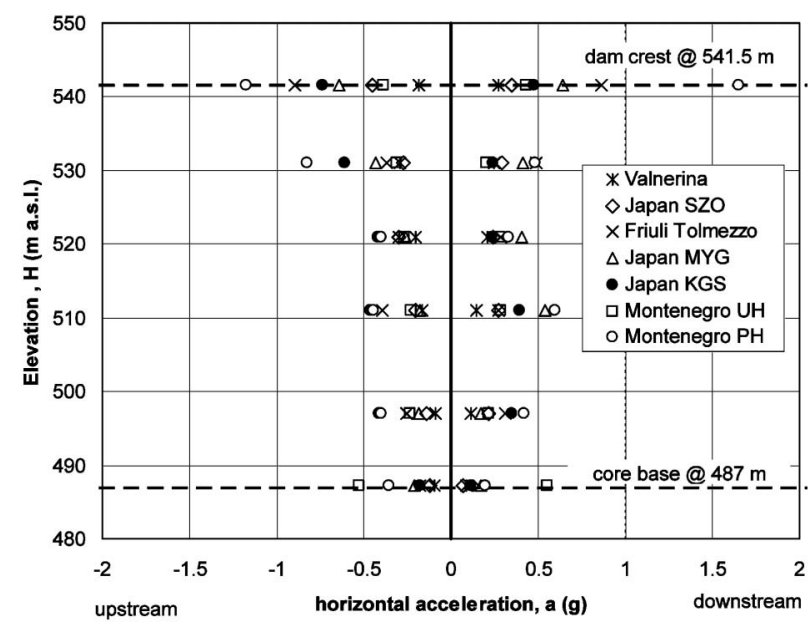

Fig. 12. Upstream (negative) and downstream (positive) acceleration profiles induced by the selected seven accelerograms along the core axis

tenegro UH earthquake, it can be observed that moving from the base to the crest of the core, there is always an amplification of the acceleration amplitude. This effect is more pronounced for the Montenegro PH event, when the downstream direction is taken into account.

\section{Seismic-induced Permanent Settlements}

A first indication about earth dam seismic response is 
obtained from the permanent settlements that occurred at the crest (that also corresponds to the dam freeboard loss). In Fig. 13 the permanent settlements of the crest (in correspondence to the core axis) have been plotted versus the Arias intensity $I_{\mathrm{a}}$ of the input motions. The Arias intensity has been preferred to other ground motion synthetic parameters as it reflects three important ground motion characteristics: amplitude, frequency content and duration (Kramer, 1996). With exception of the signals Japan MYG and Montenegro UH, the permanent settlements of the dam crest increase almost linearly with the Arias intensity of the signals and assume the maximum value of $28 \mathrm{~cm}$ for the Montenegro PH accelerogram. The latter one, even though characterized by a lower PGA than other two signals (see Table 3 ) has a longer duration of the strong-motion phase and a dominant frequency $f_{\mathrm{p}}$ equal to $2.27 \mathrm{~Hz}$. This value is quite close to the first natural frequency of the dam embankment in the

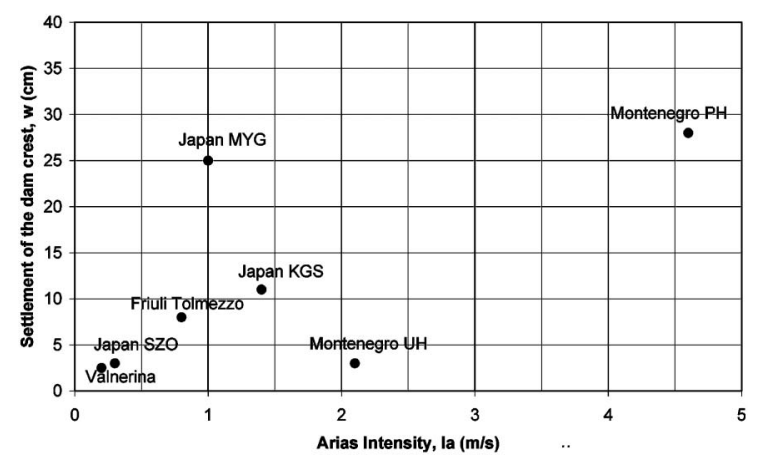

Fig. 13. Permanent settlements computed at the dam crest versus the Arias intensity of the expected earthquakes transversal direction $(3 \mathrm{~Hz})$, as obtained by interpreting several weak motion events recorded by the Camastra Dam seismic network (Sica et al., 2008).

The Montenegro UH signal, even characterized by a higher PGA and longer duration, induces a lower permanent settlement at the dam crest. This behaviour can be explained by invoking the frequency content of this record (Fig. 9(b)), shifted towards higher frequencies $(>10 \mathrm{~Hz})$ and quite far from the first natural frequency of the structure. The lower permanent settlement predicted at the dam crest is consistent with the acceleration deamplification with increasing dam elevation, as already observed in Fig. 12.

A quite unexpected result is represented by the permanent settlement of the dam crest due to the Japan MYG signal (PGA of only $0.26 \mathrm{~g}$ ). The long duration of this event (about 30 seconds with 15.45 seconds of the strongmotion phase) may justify this prediction. The constitutive model assigned to the dam soils (Hujeux model) is suitable, in fact, to model the development of plastic strains even for cyclic loads internal to the first loading curve, enhancing in this way embankment compaction and spreading with the number of cycles.

Permanent settlement contours (Figs. 14 and 15) and profiles (Fig. 16) evidence that the predicted freeboard loss is essentially due to strains experienced in the uppermost part of the embankment. The rapid changes of displacement with depths near to the dam crest recall the well-known "whiplash effect" studied by Dakoulas and Gazetas (1985).

The deformed shapes of the dam (Fig. 17) further show that settlements take place with a significant reduction in the embankment volume and are slightly higher on the upstream side (see the events of Montenegro PH and

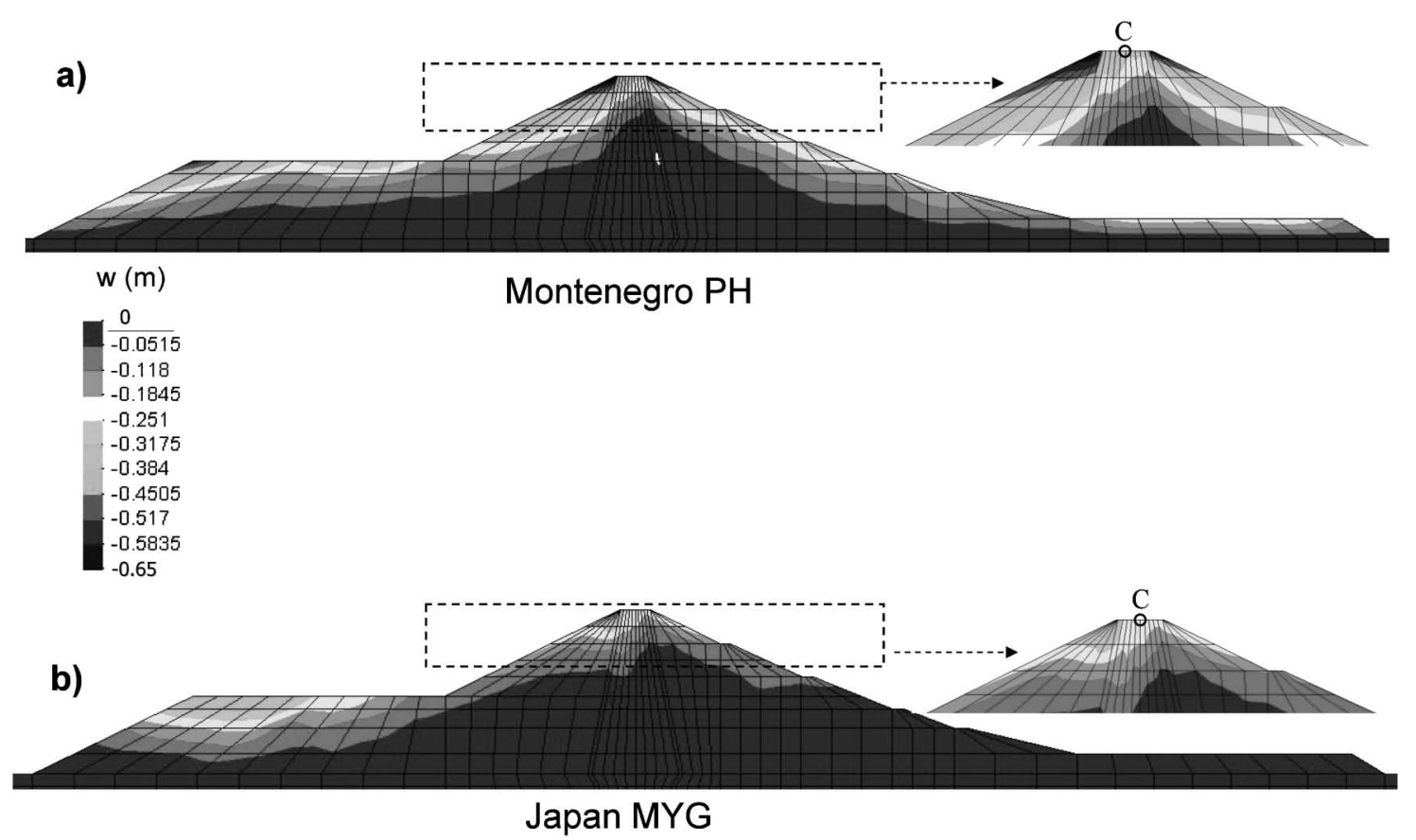

Fig. 14. Contour of permanent settlements induced by the Montenegro PH (a) and Japan MYG (b) signal 


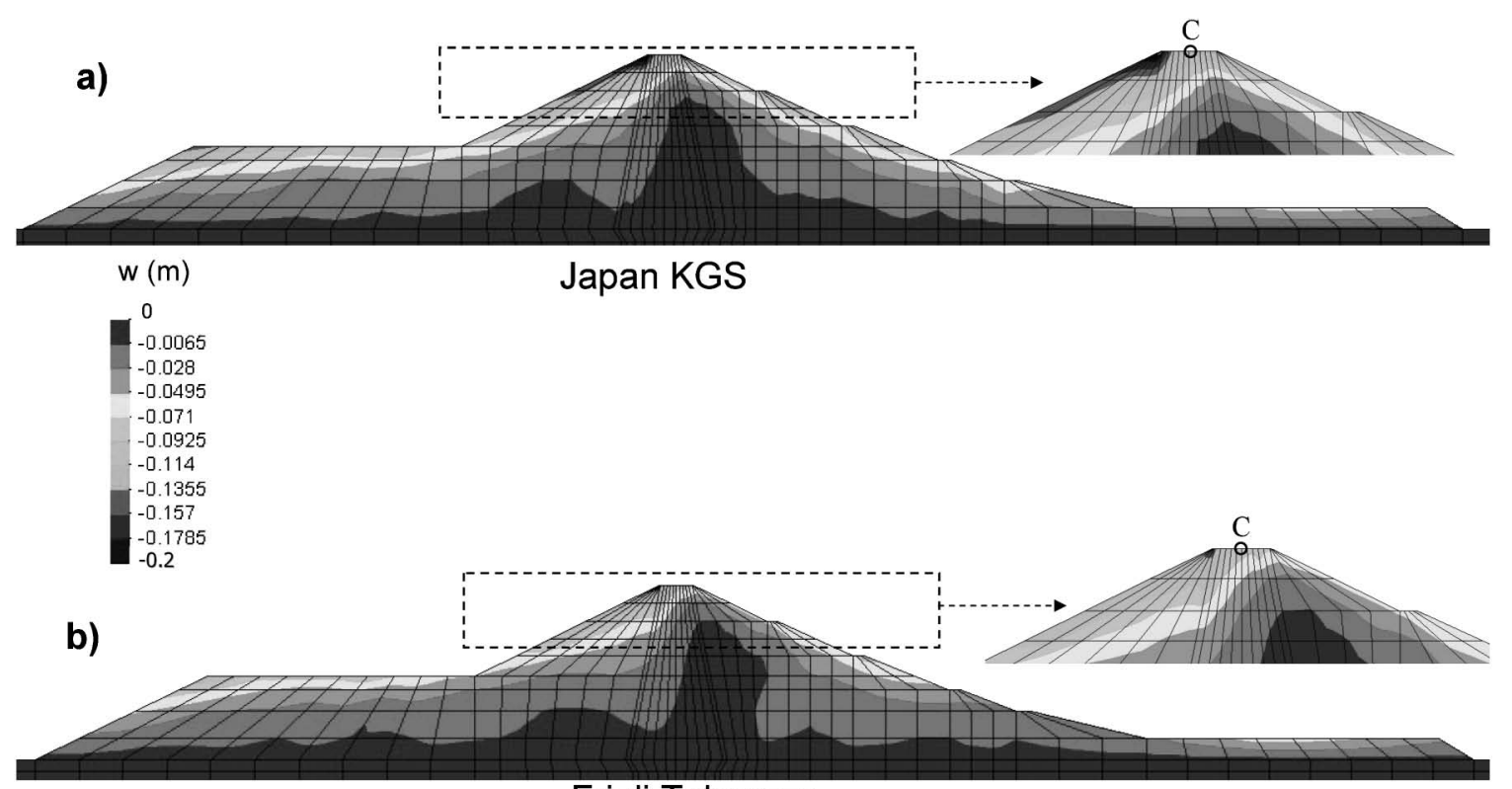

Friuli Tolmezzo

Fig. 15. Contour of permanent settlements induced by the Japan KGS (a) and Friuli Tolmezzo (b) signal
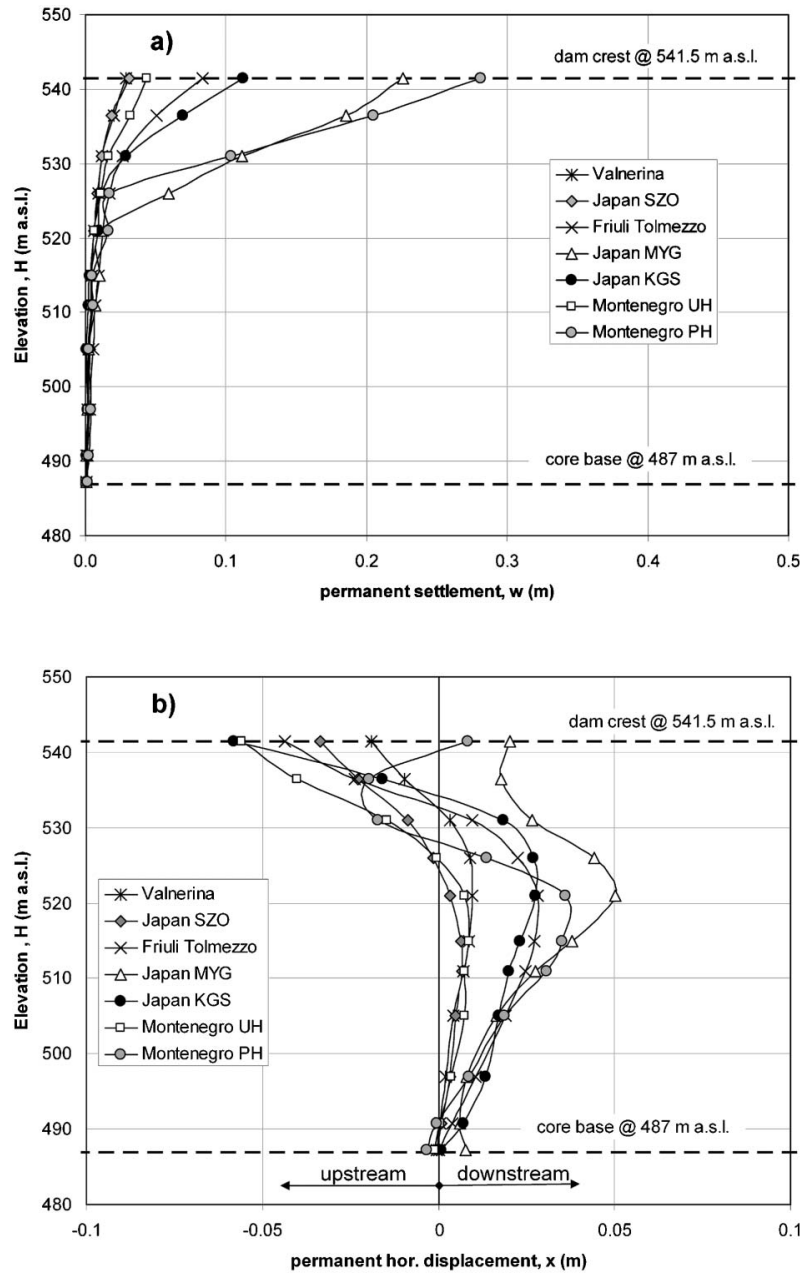

Fig. 16. Permanent settlements (a) and horizontal displacement (b) induced by the seven selected accelerograms along the core axis
Japan MYG), due to a significant distortion of the core axis. With regard to this latter effect permanent horizontal displacements plotted along the core axis (Fig. 16(b)) indicate an upstream movement in the uppermost part of the embankment and a downstream movement in the lowermost part. The computed plastic deflection of the core axis (with one inversion of the sign) resembles that typical of a higher-than-one vibration mode.

Computed displacements should be compared with threshold values assumed tolerable for the dam. HynesGriffin and Franklin (1984) recommended 1 meter of permanent displacement as a possible upper limit, admitting (questionable) that such a value should be tolerable in most dams without threatening the integrity of the reservoir, although serious damage could be observed. On the basis of the observed seismic-performance of earth dams during past earthquakes (see Table 4), it can be argued that earth dams did not suffer damage (with respect to water tightness) when the permanent settlement at the dam crest was lower than $1 \%$ of the maximum embankment height $H$. This value can be, hence, adopted as a plausible limit threshold to assess dam performance.

From Fig. 13 it can be deduced that even for the stronger earthquakes (return period $>$ than 5000 years) the permanent settlement of the Camastra Dam crest (in correspondence to the core axis) is utmost equal to $0.5 \%$ of the maximum height of the dam, i.e., well below the threshold value assumed as tolerable for the dam. This indicates a satisfactory performance of the dam.

The computed permanent settlement at the dam crest can be also considered a representative indicator of global instability phenomena, in the sense that below the above settlement threshold global sliding is not likely to occur.

\section{Liquefaction Potential Assessment}

The selected numerical tool allows to compute the dy- 


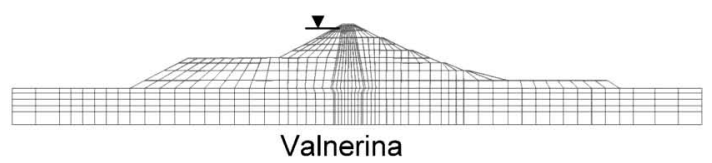

Valnerina

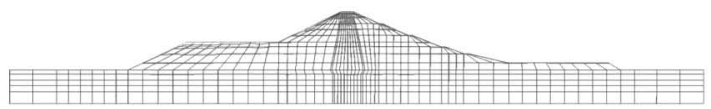

Montenegro UH

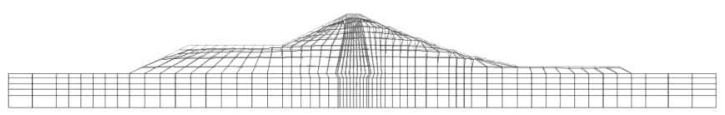

Japan KGS

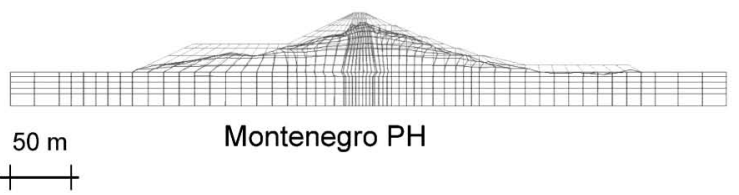

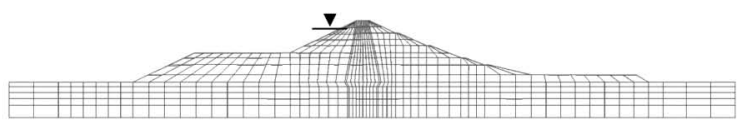

Japan SZO

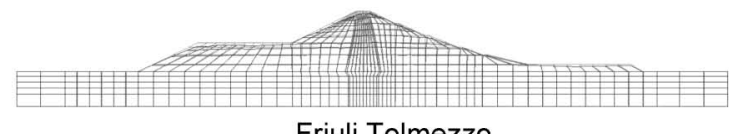

Friuli Tolmezzo

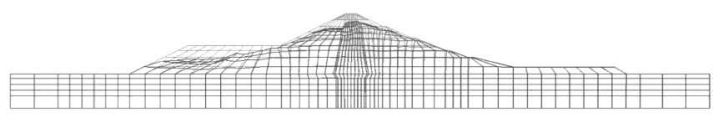

Japan MYG

displacement $=30$

Fig. 17. Seismic-induced deformed shapes of the embankment

namic pore water pressures generated in the zones of the embankment where a coupled formulation has been adopted. Figure 18 shows, for instance, the evolution of the pore water pressures generated in three nodes of the dam axis by the seism Montenegro PH, which caused the maximum effect in terms of permanent settlements at the dam crest. The three nodes are located at different elevations along the dam axis and it could be observed that the node close to the dam base (node 332 at elevation $491 \mathrm{~m}$ a.s.1.) tends to develop positive excess pore water pressures while the upper node (348 at elevation $511 \mathrm{~m}$ a.s.1.) tends to dilate. This effect makes the pore water pressures at the end of the dynamic analysis lower than the initial value provided by the static analysis.

For the node 332, Fig. 19(a) shows the evolution of the pore water pressures for the seven input motions considered in this study.

If the liquefaction factor $r_{\mathrm{u}}$ is defined as the ratio between the final excess pore water pressure and the initial vertical effective stress $\left(r_{\mathrm{u}}=\Delta u / \sigma_{\mathrm{vo}}^{\prime}\right)$, liquefaction is conventionally assumed to occur when this factor is 1 . The variability of $r_{\mathrm{u}}$ within the dam core allows to assess the susceptibility to liquefaction of such soils. In the case in hand, for the reference node 332, where higher positive excess pore water pressures were computed, the liquefaction factor $r_{\mathrm{u}}$ (Fig. 19(b)) resulted well below the limit threshold $\left(r_{\mathrm{u}}=1\right)$ assumed to trigger soil liquefaction.

\section{Hydraulic Fracturing of the Core}

Recalling the mechanisms producing core hydraulic fracturing during the operational stages, the distribution of total stresses computed within the core after the seismic simulation aids in detecting the state conditions likely to generate a crack.
In static conditions it is often assumed that (e.g., Sherard, 1986; Talbot and Deal, 1993; Dounias et al., 1996) if the minimum total stress $\sigma_{3}$ at a point of the core is below the reservoir pressure $\left(\gamma_{\mathrm{w}} z_{\mathrm{w}}\right)\left(\gamma_{\mathrm{w}}=\right.$ water specific weight; $z_{\mathrm{w}}=$ point depth below the maximum impounding level) a fracture may form or an existing one may propagate due to seepage forces.

It is well-known that core arching may contribute to make the reservoir pressure in the core higher than the minimum total stress. If under seismic actions the core deforms more than the shells, core arching may be further enhanced.

A verification of core hydraulic fracturing may be, hence, carried out by checking that after each earthquake the stress ratio $\sigma_{3} /\left(\gamma_{\mathrm{w}} z\right)$ remains higher than unity. If this condition is satisfied, even fractures formed in the core during the seismic actions are not able to propagate. Conversely, fractures may propagate from upstream to downstream and erosion phenomena may occur inside.

In order to assess dam safety against hydraulic fracturing, at the end of the dynamic analyses the hydraulic safety factor $\sigma_{3} /\left(\gamma_{\mathrm{w}} z\right)$ was computed for some points along the core axis. From Fig. 20 it can be observed that the hydraulic safety factor is higher than 1 in the pre-seismic condition. At the end of the dynamic analyses, the hydraulic safety factor tends to assume values lower than 1 for the two signals labelled Montenegro PH and Japan MYG. In such cases, the occurrence of hydraulic fracturing in the dam core should be taken into account, specially at higher elevations.

\section{CONCLUDING REMARKS}

After detecting the objectives related to the seismic verification of earth dams, i.e., the phenomena (seismic 
Table 4. Observed performance of earth dams during past earthquakes

\begin{tabular}{|c|c|c|c|c|c|c|}
\hline Dam & Typology & $H(\mathrm{~m})$ & PGA (g) & Date $d / m / y$ & Crest settl. $(\mathrm{cm})$ & Crest settl. \% of $H$ \\
\hline Gosho (Japan) & Rockfill & 52 & 0.75 & $26 / 05 / 83$ & & \\
\hline Anbuklao (Filippine) & Rockfill & 129 & 0.35 & $16 / 07 / 90$ & 80 & 0.62 \\
\hline Leroy Anderson (USA) & Rockfill & 72 & 0.41 & & 1.5 & 0.02 \\
\hline Cogoti (Cile) & Rockfill & 84 & 0.2 & & 38.1 & 0.45 \\
\hline Makio (Japan) & Rockfill & 107 & $0.3-0.51$ & $-/ 9 / 1984$ & & 0.00 \\
\hline Miboro (Japan) & Rockfill & 131 & 0.2 & $00 / 08 / 1961$ & 3 & 0.02 \\
\hline Minase (Japan) & Rockfill & 67 & 0.05 & & 6.1 & 0.09 \\
\hline Namioka (Japan) & Rockfill & 52 & $0.08-0.096$ & $01 / 05 / 83$ & 5.72 & 0.11 \\
\hline Coyote Lake (California) & Rockfill & 43 & $0.9-1.3$ & $24 / 04 / 84$ & 6.7 & 0.16 \\
\hline Acciano (Italy) & Zoned & 28.5 & $0.3-0.5$ & $25 / 09 / 97$ & 20 & 0.70 \\
\hline El Infiernillo (Mexico) & Zoned & 145 & $\begin{array}{c}0.10-0.12 \\
0.087 \\
0.132\end{array}$ & $\begin{array}{c}14 / 03 / 79 \\
\text { nov-75 } \\
19 / 09 / 85\end{array}$ & $\begin{array}{c}11 \\
2.92 \\
10.22\end{array}$ & $\begin{array}{l}0.08 \\
0.02 \\
0.07\end{array}$ \\
\hline Matahina (New Zeland) & Zoned & 86 & $0.1-0.2$ & $02 / 03 / 87$ & 10 & 0.12 \\
\hline La Villita (Mexico) & Zoned & 60 & $\begin{array}{c}0.13 \\
0.039 \\
0.017 \\
-\end{array}$ & $\begin{array}{c}19 / 09 / 85 \\
\text { nov-75 } \\
14 / 03 / 79 \\
01 / 10 / 81\end{array}$ & $\begin{array}{c}40 \\
1.8 \\
3 \\
4.8\end{array}$ & $\begin{array}{l}0.67 \\
0.03 \\
0.05 \\
0.08\end{array}$ \\
\hline Miho (Japon) & Zoned & 95 & 0.025 & $\begin{array}{l}16 / 06 / 76 \\
29 / 06 / 80\end{array}$ & & 0.00 \\
\hline Oroville (California) & Zoned & 213 & $\begin{array}{c}0.09 \\
0.1\end{array}$ & $\begin{array}{c}01 / 08 / 75 \\
-\end{array}$ & $\begin{array}{c}1 \\
0.1\end{array}$ & $\begin{array}{l}0.00 \\
0.00\end{array}$ \\
\hline Sheffield (California) & Zoned & 26 & & 1925 & Global instability & \\
\hline Yamanaka (Japan) & Zoned & - & & $16 / 05 / 68$ & Global instability & \\
\hline Tsengwen (Taiwan) & Zoned & 133 & $\begin{array}{l}0.03 \\
0.15\end{array}$ & $\begin{array}{c}21 / 09 / 99 \\
1985\end{array}$ & $\begin{array}{c}2.66 \\
4\end{array}$ & $\begin{array}{l}0.02 \\
0.03\end{array}$ \\
\hline Nanhua (Taiwan) & Zoned & 87.5 & 0.037 & $21 / 09 / 99$ & 0.875 & 0.01 \\
\hline Mudan (Taiwan) & Zoned & 62.5 & $<0.1$ & $21 / 09 / 99$ & 1 & 0.02 \\
\hline Jenyitan (Taiwan) & Zoned & 28 & 0.68 & $21 / 09 / 99$ & 2.8 & 0.10 \\
\hline Tousheh (Taiwan) & Zoned & 21.8 & 0.46 & $21 / 09 / 99$ & 27.47 & 1.26 \\
\hline Hebgen (USA) & Zoned concrete core & 25 & 0.4 & $17 / 08 / 59$ & 84 & 3.36 \\
\hline Lantan (Taiwan) & Zoned concrete core & 31 & 0.25 & $21 / 09 / 99$ & 2.48 & 0.08 \\
\hline Wushantou (Taiwan) & Hydr. fill & 56 & $\begin{array}{l}<0.1 \\
0.024\end{array}$ & $\begin{array}{c}21 / 09 / 99 \\
1986\end{array}$ & 2.8 & 0.05 \\
\hline Upper San Fernando (California) & Hydr. fill & 20 & $0.5-0.6$ & $09 / 02 / 71$ & 90 & 4.50 \\
\hline Lower San Fernando (California) & Hydr. fill & 40 & $0.5-0.6$ & $09 / 02 / 71$ & Global instability & \\
\hline Yunhoshan (Taiwan) & Homog. & 62.5 & $<0.1$ & $21 / 09 / 99$ & & 0.00 \\
\hline Chabot (California) & & 41 & & 1906 & 40 & 0.98 \\
\hline Los Angeles & Zoned & 50 & 0.42 & $17 / 01 / 94$ & 9 & 0.18 \\
\hline
\end{tabular}

damages) that need to be verified and the physical quantities that should be predicted, the paper accounts for the steps followed to accomplish the seismic verification of a real case study (the Camastra Dam) by performancebased criteria. A complex and powerful theoretical tool was adopted in accordance with the structure importance and the need to predict several physical quantities to assess the dam performance. The selected theoretical tool proved to be very effective in providing a comprehensive picture of the dam performance under both static and seismic loading conditions and in representing a unique behavioural framework to accomplish all the required verification typologies. The seismic performance of the Camastra Dam was assessed with respect to those damage typologies which could affect the main task a dam should accomplish in its life: ensuring water tightness. Perma- 


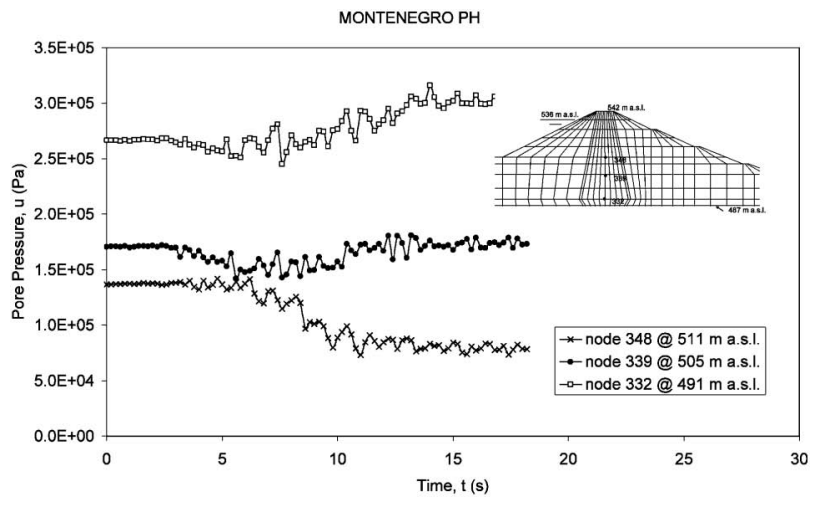

Fig. 18. Computed pore water pressures in correspondence to three nodes of the core axis under the Montenegro PH earthquake
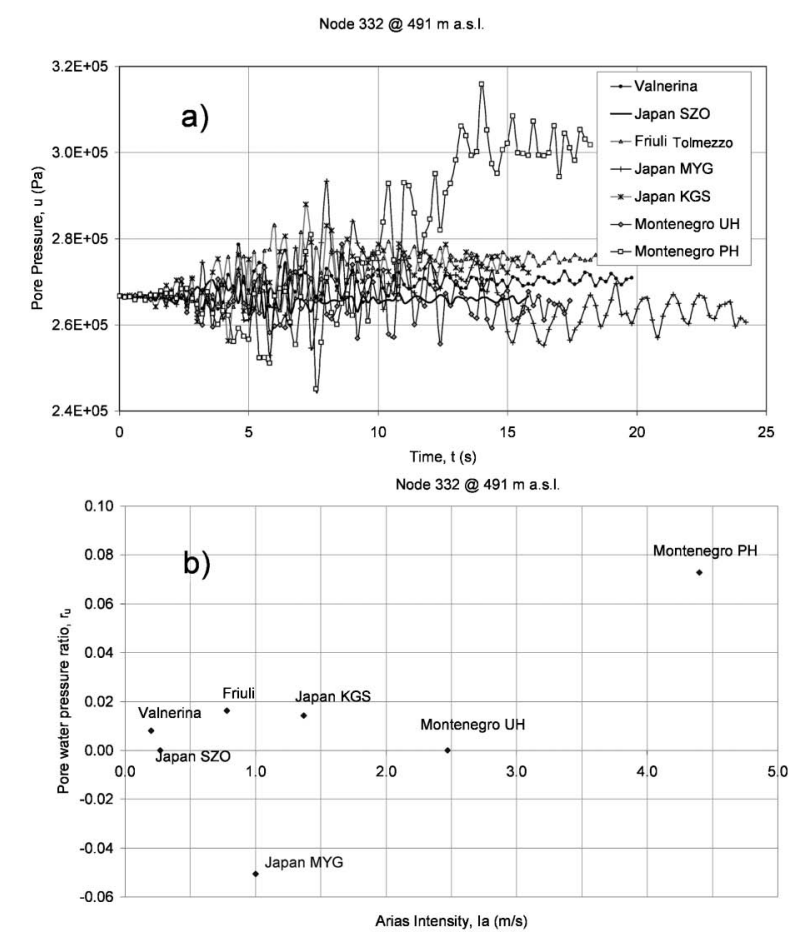

Fig. 19. Pore water pressures computed at the node 332 (491 m a.s.l.) of the core axis under the reference earthquakes: (a) pore water pressure time histories and (b) liquefaction factor $r_{\mathrm{u}}$

nent settlements, liquefaction and core fracturing were, hence, taken into account.

Worth pointing out is that if a seismic event really occurs at the dam site, the availability of refined theoretical predictions should only be intended as an additional support to monitoring activity that always remains the main tool to check dam safety. Measurement of accelerations, permanent displacements, pore water pressures, total stresses and, over all, leakage have to be promptly collected and reinterpreted to evaluate the dam post-seismic safety conditions.

\section{ACKNOWLEDGEMENTS}

This paper accounts for the research activity carried

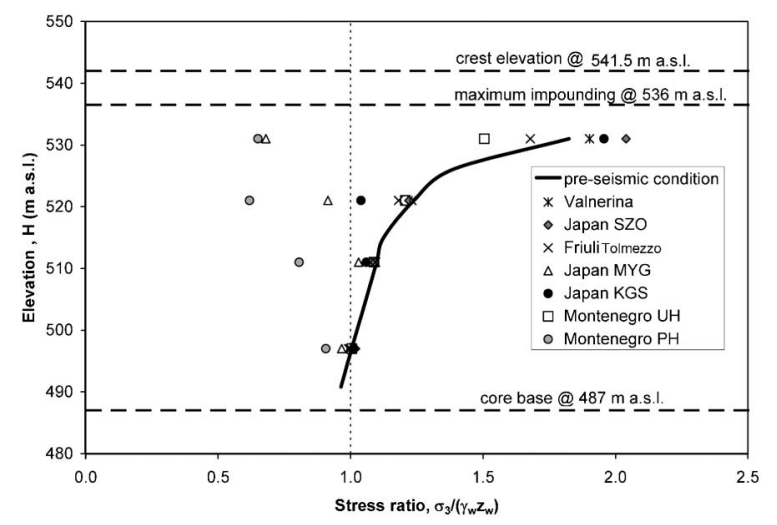

Fig. 20. Hydraulic safety factor computed along the core axis

out during the V.I.A. (Vulnerability of Infrastructures and Environment) Research Project, promoted and funded by the INGV-GNDT (National Institute of Geophysics and Volcanology). The authors wish to thank Prof. G. Calvi who was the coordinator of the V.I.A. project.

Prof. Vinale was the scientific coordinator of the Task 7 of the V.I.A. project on seismic vulnerability of earth dams. This work is dedicated to his memory.

Lucia Siervo and Agostino Napolitano are also gratefully acknowledged for their contributions to the research activity of the VIA project.

This work also was partly funded by ReLUIS (Italian University Network of Seismic Engineering Laboratories) Consortium.

\section{REFERENCES}

1) Ambraseys, N. N. (1960): The seismic stability of earth dams, Proc. 2nd World Conference on Earthquake Engineering, Tokyo, Japan, 2, 1345-1363.

2) Aubry, D., Benzenati, I. and Modaressi, A. (1991): A coupled static/dynamic strain and pore pressure analysis for embankment dams, Dam Engineering, II(I), 53-94.

3) Aubry, D., Benzenati, I. and Modaressi, A. (1993): Numerical predictions for Model n. 1, 2, and 7, Verification of Numerical Procedures for the Analysis of Soil Liquefaction Problems (eds. by Arulanandan \& Scott), Balkema, Rotterdam, 45-66, 315-322 and $817-822$.

4) Aubry, D., Hujeux, J. C., Lassoudiere, F. and Meimon, Y. (1982): A double memory model with multiple mechanism for cyclic soil behaviour, International Symposium on Numerical Models in Geomechanics, Zurigh, 3-13.

5) Aubry, D. and Modaressi, A. (1996): GEFDYN, Manuel Scientifique, Ecole Centrale Paris, http://www.mssmat.ecp.fr/sols/ logiciels/gefdyn/notice_line/index.htm.

6) Calvi, et al. (2004): VIA - Riduzione della vulnerabilità sismica di sistemi infrastrutturali e ambiente fisico, http://gndt.ingv.it/Att_ scient/PE2002_Brief_Reports/brief_reports_con_int.htm.

7) Convertito, V. and Herrero, A. (2004): Influence of focal mechanism in probabilistic seismic hazard analysis, Bulletin of the Seismological Society of America, December 2004, 94(6), 2124-2136.

8) Dafalias, Y. F. and Herrmann, L. R. (1982): Bounding surface formulation of soil plasticity, Soil Mechanics-Transient and Cyclic Loads (eds. by Pande \& Zienkiewicz ), John Wiley \& Sons.

9) Dafalias, Y. F. and Popov, E. P. (1975): A model of non-linearity hardening materials for complex loadings, Acta Mech, 21, 173-192.

10) Dounias, G. T., Potts, D. M. and Vaughan, P. R. (1996): Analysis of progressive failure and cracking in old British dams, Geotech- 
nique, London, England, 46(4), 621-640.

11) Fujii, H., Kunimasa, K., Nanba, A., Yokomizo, T., Nishimura, S., Shimada, K., Hori, T. and Nishiyama, T. (2000): Damage factors for small embankment dams due to the Hyogoken-Nambu earthquake - Case study on Hokundan Town, Soils and Foundations, 40(6), 117-131.

12) Hicher, P. Y. and Michali, A. (1996): Identifying soil parameters by means of laboratory and in situ testing, Computers \& Geotechnics, 19(2), 153-170.

13) Hynes-Griffin, M. E. and Franklin, A. G. (1984): Rationalizing the Seismic Coefficient Method, Miscellaneous Paper GL-84-13, US Army Corps of Engineers Waterways Experiment Station, Vicksburg, Mississippi.

14) Idriss, I. M. and Boulanger, R. (2004): Semi-empirical procedures for evaluating liquefaction potential during earthquakes, Proc. 11th ICSDEE \& 3rd ICEGE, (eds. by Doolin et al.), Berkeley, CA, USA, (1), 32-56.

15) Ishihara, K. (2001): Estimate of relative density from in-situ penetration tests, Proc. Int. Conf. on In Situ Measurement of Soil Properties and Case Histories, Bali, 17-26.

16) Ishihara, K. and Okada, S. (1982): Effects of large pre-shearing on cyclic behaviour of sand, Soils and Foundations, 22, 109-125.

17) Iwasaki, T., Tokida, K., Tatsuoka, F., Yasuda, S. and Sato, H. (1982): Microzonation for soil liquefaction potential using simplified methods, Proc. 3rd. Int. Conf. on Microzonation, Seattle, (3), 1319-1330.

18) Kramer, S. L. (1996): Geotechnical Earthquake Engineering, Prentice-Hall Inc., New Jersey.

19) Lopez-Caballero, F. and Modaressi Farahmand-Razavi, A. (2008): Numerical simulation of liquefaction effects on seismic SSI, Soil Dyn. and Earth. Eng., 28, 85-98.

20) Makdisi, F. I. and Seed, H. B. (1978): Simplified procedure for estimating dam and embankment earthquake-induced deformations, Journal of Geotechnical Engineering Division, ASCE, 104(GT7), 849-867.

21) Mayne, Martin, Schneider (1999): Small- and large-strain soil properties from seismic flat dilatometer tests, Proc. Pre-failure Deformation Characteristics of Geomaterials (eds. by Jamiolkowski et al.), Torino, 419-426.

22) McGuire, R. K. (1995): Probabilistic seismic hazard analysis and design earthquakes: Closing the loop, Bull. Seism. Soc. Am., 85, 1275-1284.

23) Meletti, C. and Valensise, G. (2004): Zonazione sismogenetica ZS9, Gruppo di Lavoro per la redazione della mappa di pericolosita sismica (OPCM 3274/2003), Biblioteca INGV (in Italian).

24) Meletti, C., Patacca, E. and Scandone, P. (2000): Construction of a seismotectonic model: the case of Italy, Pageoph., 157, 11-35.

25) Mroz, Z. (1967): On the description of anisotropic work-hardening, J. Mech. Phys. Solids, 15, 163-175.

26) Mroz, Z., Norris, V. A. and Zienkiewicz, O. C. (1981): An anisotropic critical state model for soils subjected to cyclic loading, Geotechnique, 31, 451-469.

27) Newmark, N. W. (1965): Effects of earthquakes on dams and embankments, The 5th Rankine Lecture of the British Geotechnical Society, Géotechnique, 15(2), 139-160.

28) Ozkan, Y. (1998): A review of considerations on seismic safety of embankments and earth and rock fill dams, Soil Dynamic and Earthquake Engineering, 17, 439-458.

29) Pagano, L. (1998): Steady state and transient unconfined seepage analysis for earthfill dams, Proc. VIII ABAQUS Users' Conference, Milano, 577-585.

30) Pagano, L., Desideri, A. and Vinale, F. (1998): Interpreting the settlement profiles of earth dams, Journal of Geotechnical and Geoenvironmental Engineering, ASCE, 124(10), 923-932.

31) Pagano, L., Sica, S. and Desideri, A. (2006): Representativeness of measurements in the interpretation of earth dam behavior, Canadian Geotechnical Journal, 43(1), 87-99.

32) Paoliani, P. (2001): The behaviour of Acciano earth dam during the Umbria-Marche earthquake of September 1997, Rivista Italiana di Geotecnica, (2), 20-27.
33) Pastor, M., Zienkiewicz, O. C. and Chan, A. H. C. (1990): Generalized plasticity and the modelling of soil behaviour, Int. J. Num. Anal. Meth. Geomech., 14, 151-190.

34) Prevost, J. H. (1978): Anisotropic undrained stress-strain behaviour of clays, Journal of Geotechnical Engineering Division, 1076-1090.

35) Prevost, J. H. (1985): Wave propagation in fluid-saturated porous media: an efficient finite element procedure, Soil Dyn. Earth. Eng., 4(4), 183-202.

36) Resendiz, D., Romo, M. P. and Moreno, E. (1982): El Infiernillo and La Villita Dams: Seismic behaviour, Journal of Geotechnical Engineering, ASCE, 108(GT1), 109-131.

37) Rollins, K. M., Evans, M. D., Diehl, N. B. and Daily, W. D. (1998): Shear modulus and damping relationships for gravels, Journal of Geotechnical and Geoenvironmental Engineering, 396-405.

38) Scandone, P. and Stucchi, M. (2000): La zonazione sismogenetica ZS4 come strumento per la valutazione della pericolosita sismica, Le ricerche del GNDT nel campo della pericolosita sismica 1996-1999, Gruppo Nazionale Difesa Terremoti, 3-14 (in Italian).

39) Seed, H. B. (1979): Considerations in the earthquake-resistant design of earth and rockfill dams, Geotechnique, 29(3), 215-263.

40) Seed, H. B. and Idriss, I. M. (1971): Simplified procedure for evaluating soil liquefaction potential, ASCE Journal of Soil Mechanics and Foundations Division, 97(9), 1249-1273.

41) Seed, H. B. and Martin, G. R. (1966): The seismic coefficient in earth dam design, ASCE. J. Soil Mechanics Foundations Div., (SM6), 105-134.

42) Seed, H. B., Wong, R. T., Idriss, I. M. and Tokimatsu, K. (1986): Moduli and damping factors for dynamic analyses of cohesionless soils, Journal of Geotechnical Engineering, ASCE, 112(11), 1016-1032.

43) Sherard, J. L. (1986): Hydraulic fracturing in embankment dams, J. Geotech. Engrg., ASCE, 110(10), 905-927.

44) Sica, S. (2003): Dynamic analysis of earth dams, Proc. Workshop in Naples on Constitutive Modeling and Analysis of Boundary Value Problems in Geotechnical Engineering, 413-459.

45) Sica, S., Pagano, L. and, Modaressi, A. (2008): Influence of past loading history on the seismic response of earth dams, Computers \& Geotechnics, 35(1), 61-85.

46) Sica, S., Pagano, L. and Vinale, F. (2008): Interpretazione dei segnali sismici registrati sulla diga di Camastra, Italian Geotechnical Journal, XLII(4), 97-111 (in Italian).

47) Singh, R., Roy, D. and Jain, S. K. (2005): Analysis of earth dams affected by the 2001 Bhuj Earthquake, Engineering Geology, 80(3-4), 282-291.

48) Talbot, J. R. and Deal, C. E. (1993): Rehabilitation of cracked embankment dams, Geotechnical Practice in Dam Rehabilitation, ASCE Geotechnical Special Publication No. 35, North Carolina State University, 267-283.

49) Terzaghi, K. (1950): Mechanisms of Landslides, The geological survey of America, Engineering Geology (Berkeley).

50) Vinale, F., Mancuso, C. and Silvestri, F. (1995): Italian experiences on dynamic in situ and laboratory measurements of soil properties, Proc. 3rd Turkish Earth. Eng. Conf., Istanbul.

51) Vucetic, M. and Dobry, R. (1991): Effect of soil plasticity on cyclic response, Journal of Geotech. Engrg., 117(1), 89-107.

52) Yegian, M. K., Marciano, E. and Gharaman, V. G. (1991): Earthquake-induced permanent deformation: probabilistic approach, Journal of Geotechnical Engineering, ASCE, 29(1), 93-104.

53) Youd, T. L., et al. (2001): Liquefaction resistance of soils: Summary report from the 1996 NCEER and 1998 NCEER/NSF workshops on evaluation of liquefaction resistance of soils, ASCE Journal of Geotechnical and Geoenvironmental Engineering, 127(10), 817-833.

54) Zienkiewicz, O. C., Chan, A. H. C., Pastor, M., Schrefler, B. A. and Shiomi, T. (1999): Computational Geomechanics with Special Reference to Earthquake Engineering, John Wiley \& Sons, New York, USA.

55) Zienkiewicz, O. C. and Shiomi, T. (1984): Dynamic behaviour of saturated porous media; the generalised Biot formulation and its 
numerical solution, International Journal for Numerical and Analytical Methods in Geomechanics, 8, 71-96.

\section{APPENDIX 1}

Referring to the specific literature (Zienkiewicz and Shiomi, 1984; Zienkiewicz et al., 1999) for a full treatment of the Biot consolidation theory, this section provides the formulation adopted in this study, the so-called u-p formulation, which consists of neglecting fluid acceleration terms and convective terms of this acceleration so that the unknown variables remain the displacement of the solid $\mathbf{u}$ and the pressure of the water $p$. As further simplifications, soil grain compressibility is assumed to be null and thermal effects are neglected. Under such hypotheses the set of governing equations is: Overall equilibrium for the soil-fluid mixture

$$
\mathbf{S}^{T} \boldsymbol{\sigma}-\rho \ddot{\mathbf{u}}+\rho \mathbf{b}=0
$$

Equilibrium of the water + flow conservation equation (and generalized Darcy's law)

$$
\nabla^{T} \mathbf{k}\left(-\nabla p+\rho_{\mathrm{f}} \mathbf{b}\right)+\mathbf{m} \epsilon+\frac{p}{Q}=0
$$

Constitutive law

$$
d \boldsymbol{\sigma}^{\prime}=\mathbf{D} d_{\epsilon}
$$

Compatibility

$$
d \epsilon=\mathbf{S} d \mathbf{u}
$$

The boundary conditions imposed on the field variables $\mathbf{u}$ and $p$ complete the problem. The equations to be solved by finite elements are the variational form of the above equation set. They are solved using a finite difference technique time integration scheme of the Newmark-type. For the scheme to be unconditionally stable, the following integration parameters were adopted:

$$
\gamma=0.5 \text { and } \beta=0.25+(\gamma+0.5)^{2}=0.25 \text {. }
$$

\section{APPENDIX 2}

In the Hujeux model, the elastic response is assumed to be isotropic and non-linear with the bulk $(K)$ and the shear moduli $(G)$ functions of the mean effective stress according to the relations:

$$
K=K_{\text {ref }}\left(\frac{p}{p_{\text {ref }}}\right)^{n} \quad G=G_{\text {ref }}\left(\frac{p}{p_{\text {ref }}}\right)^{n}
$$

where $K_{\text {ref }}$ and $G_{\text {ref }}$ are respectively the bulk and shear modulus at the mean reference effective pressure $p_{\text {ref. }}$.

During a monotonic loading process the primary yield function associated with the generic mechanism $k$, has the following expression:

$$
f_{\mathrm{k}}\left(q_{\mathrm{k}}, p_{\mathrm{k}}, \varepsilon_{\mathrm{v}}^{\mathrm{p}}, r_{\mathrm{k}}\right)=q_{\mathrm{k}}-p_{\mathrm{k}} \sin \varphi\left(1-b \log \frac{p_{\mathrm{k}}}{p_{\mathrm{c}}}\right) r_{\mathrm{k}}
$$

where the following variables have been introduced:

$$
q_{\mathrm{k}}=\sqrt{\left(\frac{\sigma_{\mathrm{ii}}^{\prime}-\sigma_{\mathrm{jj}}^{\prime}}{2}\right)^{2}+\left(\sigma_{\mathrm{ij}}^{\prime}\right)^{2}},
$$

the radius of the Mohr circle in the plane of the generic deviatoric mechanism of normal $\vec{e}_{\mathrm{k}}$. Here $i, j, k \in\{1,2$, $3\} ; \quad i=1+\bmod (k, 3)$ and $j=1+\bmod (k+1,2)$ with $\bmod (k, j)$ representing the residue of the division of $k$ by j;

$$
p_{\mathrm{k}}=\frac{\sigma_{\mathrm{ii}}^{\prime}-\sigma_{\mathrm{jj}}^{\prime}}{2},
$$

the centre of the Mohr circle in the plane of the deviatoric mechanism of normal $\vec{e}_{\mathrm{k}}$;

$p_{\mathrm{c}}$, the critical pressure that is linked to the volumetric plastic strain $\varepsilon_{\mathrm{v}}^{\mathrm{p}}$ by the relation $p_{\mathrm{c}}=p_{\mathrm{c}_{0}} \exp \left(\beta \varepsilon_{\mathrm{v}}^{\mathrm{p}}\right)$, where $p_{\mathrm{c}_{0}}$ represents the initial critical pressure and $\beta$ the plastic compressibility of the material in the isotropic plane (ln $\left.p^{\prime}, \varepsilon_{\mathrm{v}}^{\mathrm{p}}\right)$.

$\varphi$, the soil friction angle at perfect plasticity;

$b$, a numerical parameter which controls the shape of the loading function ( $b=0$ for Mohr Coulomb surface type; $b=1$ for Cam Clay surface type);

$r_{\mathrm{k}}$, degree of mobilized friction of the deviatoric mechanism $k$.

The last variable is linked to the plastic shear strain $\varepsilon_{\mathrm{dk}}^{\mathrm{p}}$ by the following hyperbolic function:

$$
r_{\mathrm{k}}=r_{\mathrm{k}}^{\mathrm{el}}+\frac{\int d \varepsilon_{\mathrm{d} \kappa}^{\mathrm{p}} d t}{a+\int d \varepsilon_{\mathrm{d} \kappa}^{\mathrm{p}} d t}
$$

where $a$ is a parameter which regulates the deviatoric hardening of the material. It varies between $a_{1}$ and $a_{2}$ such that:

$$
a=a_{1}+\left(a_{2}-a_{1}\right) \alpha_{\mathrm{k}}\left(r_{\mathrm{k}}\right)
$$

where:

$$
\begin{array}{ll}
\alpha_{\mathrm{k}}\left(r_{\mathrm{k}}\right)=0 & \text { if } \quad r_{\mathrm{k}}<r_{\mathrm{k}}^{\text {hys }} \\
\alpha_{\mathrm{k}}\left(r_{\mathrm{k}}\right)=\left(\frac{r_{\mathrm{k}}-r^{\text {hys }}}{r^{\text {mob }}-r^{\text {hys }}}\right)^{m} & \text { if } \quad r_{\mathrm{k}}^{\text {hys }}<r_{\mathrm{k}}<r_{\mathrm{k}}^{\text {mob }} \\
\alpha_{\mathrm{k}}\left(r_{\mathrm{k}}\right)=1 & r_{\mathrm{k}}^{\text {mob }}<r_{\mathrm{k}}<1
\end{array}
$$

$r_{\mathrm{k}}^{\mathrm{el}}$ defines the elastic limit while $r_{\mathrm{k}}^{\mathrm{hys}}$ and $r_{\mathrm{k}}^{\mathrm{mob}}$ designate the extent of the domain where hysteretic degradation occurs. The parameter $r_{\mathrm{k}}^{\mathrm{el}}$ and $r_{\mathrm{k}}^{\text {hys }}$ may be linked via the Eq. (A2.3) to the shear strain thresholds, $\gamma_{1}$ and $\gamma_{\text {vol }}$, respectively.

In the model an associated flow rule is assumed for each deviatoric mechanism in the relative plane while a non-associated Roscoe type dilatancy law is assumed for the volumetric plastic strain of each deviatoric mechanisms: 


$$
\frac{\partial \varepsilon_{\mathrm{vk}}^{\mathrm{p}}}{\partial \varepsilon_{\mathrm{dk}}^{\mathrm{p}}}=\alpha_{\mathrm{k}}\left(r_{\mathrm{k}}\right)\left(\sin \psi-\frac{q_{\mathrm{k}}}{p_{\mathrm{k}}}\right)
$$

with $\psi$ representing the dilatancy angle. It should be noted that no volumetric plastic strain is generated before $r_{\mathrm{k}}^{\mathrm{hys}}$, thus its value can be estimated with respect to the volumetric strain threshold.

Whenever a stress reversal occurs, the primary yield function (A2.2) is abandoned and the cyclic surface becomes active. The latter is defined by the function:

$$
\begin{gathered}
f_{\mathrm{k}}^{\mathrm{c}}\left(q_{\mathrm{k}}, p_{\mathrm{k}}, \varepsilon_{\mathrm{p}}^{\mathrm{v}}, r_{\mathrm{k}}^{\mathrm{cyc}}, c_{\mathrm{k}}\right) \\
=\left[q_{\mathrm{k}}-c_{\mathrm{k}}\right]-p_{\mathrm{k}} \sin \varphi\left(1-b \log \frac{p_{\mathrm{k}}}{p_{\mathrm{c}}}\right) r_{\mathrm{k}}^{\mathrm{cyc}} \\
\text { where } r_{\mathrm{k}}^{\mathrm{cyc}}=r_{\mathrm{k}}^{\mathrm{el}}+\frac{\int d \varepsilon_{\mathrm{dk}}^{\mathrm{p}} d t}{a+\int d \varepsilon_{\mathrm{dk}}^{\mathrm{p}} d t}
\end{gathered}
$$

represents the mobilization degree during the cyclic loading process and $c_{\mathrm{k}}$ is a kinematic hardening parameter, which depends on the stress ratio in the plane of the mechanism $k$ at the moment of the stress reversal. Whenever a reversal of loading occurs, the variables $r_{\mathrm{k}}^{\mathrm{cyc}}$ and $c_{\mathrm{k}}$ are discontinuously updated (Aubry et al., 1982). The model takes into account plastic volumetric and deviatoric strains developed during unloading-reloading processes, linking the amount of these strains to the level of the stress ratio from which loading reversal takes place such as observed from experimental data (Ishihara and Okada, 1982).

Finally, the constitutive equation set completes with the equations describing the isotropic yield function which allows the definition of the last mechanism $(k=4)$ of the model. The isotropic yield function is assumed to be:

$$
f\left(p, \varepsilon_{\mathrm{v}_{\mathrm{i}}}^{\mathrm{p}}\right)=p-p_{\mathrm{c}} r_{4} d
$$

where $p$ and $p_{\mathrm{c}}$ are respectively the current and critical state mean effective pressures. The parameter $d$ represents the distance between the isotropic consolidation line and the critical state line in the $(\ln \mathrm{p}, \mathrm{e})$ plane while $c$ is a model parameter controlling the volumetric hardening of soil as:

$$
r_{4}=r_{4}^{\mathrm{el}}+\frac{\int d \varepsilon_{\mathrm{v} 4}^{\mathrm{p}} d t}{c p_{\mathrm{c}} / p_{\mathrm{ref}}+\int d \varepsilon_{\mathrm{v} 4}^{\mathrm{p}} d t}
$$

All mechanisms are coupled through the total volumetric plastic strain given by:

$$
d \varepsilon_{\mathrm{v}}^{\mathrm{p}}=d \varepsilon_{\mathrm{v}_{1}}^{\mathrm{p}}+d \varepsilon_{\mathrm{v}_{2}}^{\mathrm{p}}+d \varepsilon_{\mathrm{v}_{3}}^{\mathrm{p}}+d \varepsilon_{\mathrm{v}_{4}}^{\mathrm{p}}
$$

Further analytical details concerning the model can be found in the specific reference (Aubry et al., 1982; Aubry and Modaressi, 1996).

\section{LIST OF SYMBOLS}

$\mathbf{S}=\left|\begin{array}{ll}\frac{\partial}{\partial x} & 0 \\ 0 & \frac{\partial}{\partial y} \\ \frac{\partial}{\partial x} & \frac{\partial}{\partial y}\end{array}\right|$

$\begin{array}{ll}\sigma & \text { total stress tensor } \\ \rho & \text { total density } \\ \mathbf{u} & \text { solid displacement vector } \\ \mathbf{b} & \text { body force per unit mass } \\ \mathbf{k} & \text { soil permeability tensor } \\ p & \text { pressure of the water } \\ \rho_{\mathrm{f}} & \text { water density } \\ \mathbf{m}=[111999]^{T} \\ \epsilon & \text { strain tensor } \\ n & \text { porosity } \\ K_{\mathrm{f}} & \text { bulk modulus of the water } \\ K_{\mathrm{s}} & \text { bulk modulus of the solid skeleton }\end{array}$

$\frac{1}{Q}=\frac{n}{K_{\mathrm{f}}}+\frac{1-n}{K_{\mathrm{s}}}$

D constitutive tangent matrix

$\sigma^{\prime} \quad$ effective stress tensor

$I_{\mathrm{p}} \quad$ plasticity index

$w_{1} \quad$ liquid limit

$q \quad$ deviatoric stress

$p^{\prime} \quad$ mean effective stress

$G \quad$ shear modulus

$G_{\mathrm{o}} \quad$ initial shear modulus

$n$ exponent regulating the variation of the bulk and shear modulus with the mean effective pressure shear strain

$\gamma_{1} \quad$ linear shear strain threshold

$\gamma_{\text {vol }} \quad$ volumetric shear strain threshold

$K$ bulk modulus

$p_{\text {ref }} \quad$ mean reference effective pressure

$K_{\text {ref }} \quad$ bulk modulus at the mean reference effective pressure

$G_{\text {ref }} \quad$ shear modulus at the mean reference effective pres-

$$
\text { sure }
$$

$\epsilon_{\mathrm{v}}^{\mathrm{p}} \quad$ total volumetric plastic strain

$\varepsilon_{\mathrm{d}}^{\mathrm{p}} \quad$ total deviatoric plastic strain

$\varepsilon^{\mathrm{p}} \quad$ total plastic strain

$\varepsilon_{\mathrm{dk}}^{\mathrm{p}} \quad$ deviatoric plastic strain of the mechanism $k(k=1$, $2,3)$

$\varepsilon_{\mathrm{vk}}^{\mathrm{p}} \quad$ volumetric plastic strain of the mechanism $k(k=$ $1,2,3,4)$

$r_{\mathrm{k}} \quad$ degree of the mobilized friction of the deviatoric mechanism $k$

deviatoric stress of the deviatoric mechanism $k$

$p_{\mathrm{k}} \quad$ mean effective stress of the deviatoric mechanism $k$

$p_{\text {c }} \quad$ critical pressure

$p_{\mathrm{c}_{0}} \quad$ initial critical pressure 
$\beta \quad$ plastic compressibility in the isotropic plane $\left(\ln p^{\prime}\right.$, $\left.\epsilon_{\mathrm{v}}^{\mathrm{p}}\right)$

$\varphi \quad$ soil friction angle at perfect plasticity

$b \quad$ numerical parameter which controls the shape of the loading function in the deviatoric stress subspace

$a_{1}$ numerical parameter which regulates the deviatoric hardening of soil

$a_{2} \quad$ numerical parameter which regulates the deviatoric hardening of soil

$a \quad$ numerical parameter given by the following relation $a=a_{1}+\left(a_{2}-a_{1}\right) \alpha_{\mathrm{k}}\left(r_{\mathrm{k}}\right)$

$\alpha_{\mathrm{k}} \quad$ numerical parameter regulating soil dilatancy

$r_{\mathrm{k}}^{\mathrm{el}}$ degree of the mobilized friction representing the elastic limit domain in the deviatoric stress subspace of the mechanism $k$

$r_{\mathrm{k}}^{\text {hys }}$ degree of the mobilized friction representing the hysteretic limit domain in the deviatoric stress subspace of the mechanism $k$

$r_{\mathrm{k}}^{\mathrm{mob}} \quad$ degree of the mobilized friction where degradation phenomena start to occur in the deviatoric stress subspace of the mechanism $k$

dilatancy angle

$r_{\mathrm{k}}^{\mathrm{cyc}}$ mobilization degree during the cyclic loading process

$c_{\mathrm{k}} \quad$ kinematic hardening parameter

n unit normal to the yield locus

$d$ distance between the isotropic consolidation line and the critical state line in the $(\ln p, e)$ plane

$c$ numerical parameter controlling the volumetric hardening of the soil in pure isotropic stress paths elastic threshold for the volumetric mechanism $(k$ $=4$ )

$w \quad$ soil water content

$w_{\text {opt }} \quad$ water content at the optimum of the Proctor standard

PGA peak ground acceleration

$I_{\mathrm{a}} \quad$ Arias intensity

$t_{\text {strong }}$ Trifunac duration

$T_{\mathrm{p}} \quad$ dominant period

$f_{\mathrm{p}} \quad$ fundamental frequency 